Article

\title{
Enhanced Tolerance to Cadmium in Bacterial-Fungal Co-Cultures as a Strategy for Metal Biorecovery from e-Waste
}

\author{
Geremia Losa and Saskia Bindschedler* \\ Laboratory of Microbiology, Institute of Biology, University of Neuchâtel, 2000 Neuchâtel, Switzerland; \\ geremia.losa@unine.ch \\ * Correspondence: saskia.bindschedler@unine.ch
}

Received: 31 January 2018; Accepted: 14 March 2018; Published: 21 March 2018

\begin{abstract}
We investigated a microbe-based approach to be used for the biorecovery of valuable metals from e-waste. E-waste is a heterogeneous matrix at the microbial scale. Therefore, this study aims at taking advantage of bacterial-fungal (BF) interactions in order to mobilize and immobilize a selected metal present in e-waste. We used cadmium $(\mathrm{Cd})$ and a selection of $\mathrm{Cd}$-tolerant microorganisms from our culture collection or isolated from a naturally cadmium-contaminated soil. Several experiments were designed in order to use the synergistic bioremediation capabilities of BF couples to mobilize and immobilize $\mathrm{Cd}$ from a culture medium. Initial results showed that the selected synergistic BF couples are more tolerant to $\mathrm{Cd}$ concentrations than the organisms alone. However, setting the conditions leading to effective immobilization of this toxic metal still need further work. Using microbial consortia rather than single species represents an innovative alternative to traditional bioremediation approaches for the development of new biotechnological approaches in urban mining.
\end{abstract}

Keywords: e-waste; urban mining; metal biorecovery; Bacterial-Fungal Interactions; fungal highways; cadmium; heavy-metal tolerance

\section{Introduction}

E-waste consists of end-of-life electronic and electrical equipment. It is typically composed of a mixture of metals ( $\mathrm{Fe}, \mathrm{Cu}, \mathrm{Al}, \mathrm{Au}, \mathrm{Ag}$, $\mathrm{Pd}, \mathrm{Li}$, and in lower concentration also $\mathrm{Hg}, \mathrm{Pb}, \mathrm{Cd}$, and rare-earth elements), plastics, and ceramics [1-3]. Several precious metals (e.g., $\mathrm{Au}, \mathrm{Ag}, \mathrm{Pd}$ ) are common in e-waste because of their high chemical stability and good conducting properties [2]. In 2018, e-waste will reach an amount of 50 million tones (Mt) with a projected annual growth rate of 4 to 5\% [4].

A large fraction of e-waste is disposed of in developing countries by open dumping, leading to leaching of toxic compounds into soil and groundwater [5]. In addition to this, large amounts of non-renewable raw materials are immobilized in e-waste. In order to tackle these issues, a recycling hierarchy has been proposed which includes the recycling of individual compounds in e-waste [6]. This leads to the concept of urban-mining. This concept proposes to reclaim raw resources, such as metals for instance, that are present in anthropogenic waste in order to re-insert them further in a circular economy [7]. At present day, the recycling of e-waste consists in their dismantling and to the recovery of selected precious metals through metallurgical processes previously applied in mineral ores [2]. Among metallurgical processes, hydro- and pyro- metallurgy involve the use of toxic products, high installation costs, as well as environmental and human health concerns. Beside these two physicochemical approaches, a biological approach coined biometallurgy exists [2]. This approach is investigated since 20 years and relies on the understanding of metal-microbes interactions. Biometallurgy aims at extracting and recovering precious metals through economically and ecologically friendly approaches, 
using the structural and/or catalytic proprieties of microbes [8]. Such an application is applied to exploit some mineral ores that contain a low concentration of specific metals with high economic value $(\mathrm{Cu}, \mathrm{Au}, \mathrm{Ni})$ [9]. However, at present-day, there are no biometallurgical processes available on the market for the biorecovery of metals from e-waste. This aspect represents a timely issue for ethical, environmental and societal issues. Therefore, further research in applied metal biorecovery using combinations of bacteria and fungi is needed for the development of new environmentally-friendly biotechnological approaches in the biometallurgical field.

Microbes (both eukaryotic and prokaryotic) are important actors of the biogeochemical cycles of the elements, eventually leading to important ecosystem functions such as organic matter decomposition, mineral bioweathering, and soil formation. As a result, they have a strong impact on metal mobility within ecosystems [10-12]. Metals can be classified as essential and non-essential for living organisms. Metals such as $\mathrm{Na}, \mathrm{K}, \mathrm{Cu}, \mathrm{Zn}, \mathrm{Co}, \mathrm{Ca}, \mathrm{Mg}, \mathrm{Mn}$ and Fe are essential for all microbes for structural and/or catalytic functions. Other metals such as $\mathrm{Cs}, \mathrm{Al}, \mathrm{Cd}, \mathrm{Hg}$, and $\mathrm{Pb}$ do not have an essential function but can be accumulated by microbes in order to decrease the toxicity of these metals [11]. In heavy metal contaminated soil (from natural or anthropogenic sources), microorganisms survive and proliferate due to the acquisition of tolerance mechanisms. Those mechanisms result both from phenotypic or genetic alterations [13]. The way microbes interact with metals depends on metal speciation, the microbial species involved, and the abiotic conditions. On the other hand, metal behavior (i.e., speciation, solubility, bioavailability, and toxicity) depends strongly on physicochemical conditions that are largely driven by microbial activities [11,12,14,15]. As a result, an intricate feedback exists between microbial metabolisms and metal mobility, which can be harnessed for the purpose of metal biorecovery.

Microbe-metal interactions can be divided into two different major strategies, metal mobilization and metal immobilization. Microbes can: (i) solubilize metals from minerals or metallic alloys thereby increasing metal bioavailability and mobility or (ii) immobilize metals in the form of complexes or precipitates leading to reduced metal bioavailability and mobility [16,17]. Metal mobilization by bacteria and fungi can result from redoxolysis, acidolysis or complexolysis [10,11,18]. Metal immobilization mechanisms consist mainly in biosorption, intracellular accumulation or precipitation (i.e., biomineralization). Compared to bacteria, fungi can immobilize metals inside their organelles (mostly vacuoles) and metals can be translocated and/or accumulated within fungal tissues such as rhizomorphs and fruiting-bodies [11,17,18].

Current biometallurgical or biomining approaches rely on the use of single microbial species or on consortia consisting in several bacterial species $[19,20]$. However, in the natural environment, microorganisms rarely live alone. Soil, one of the most typical microbial environments, harbors up to $10^{9}$ microbial cells in one gram of soil [21], and is the place of intense biogeochemical activity. Soils are complex and heterogeneous water unsaturated environments, where bacteria and fungi coexist and share similar ecological niches [22]. This results in numerous interactions, such as commensalism, mutualism and parasitism [23]. A major difference between fungi and bacteria is their dispersal ability and thus their distribution within soil. In soil, movement of bacteria is restricted because of the heterogeneous distribution of air-filled pores and bacteria need a continuous water phase for dispersion [24,25]. In contrast, fungi, with their filamentous lifestyle, are more adapted to bridge air-filled water gaps present in soils [26]. Therefore the colonization of soil by fungi is optimized thanks to their morphology, and the presence of hydrophobins at the hyphal surface, as well as their ability to translocate nutrients between the different modules of the organism [27-30]. Some bacteria have developed an alternative dispersal mechanism by interacting with fungi to compensate reduced dispersal capability in soils. This mechanism dubbed fungal highways (FH; [31]) is a typical example of bacterial-fungal interaction (BFI). In FH, bacteria use the fungal hyphal network as a highway in order to colonize new microhabitats $[10,26]$. Bacteria move actively, using flagella, in the synaeretic liquid film formed around fungal hyphae [31]. FH interactions have been demonstrated to be important in selected soil functions, e.g., for organic pollutant bioremediation [32-34], to resume bacterial activity 
through increased water bioavailability [35] or to activate a biogeochemical process linked to the global carbon cycle [36].

In this study, we hypothesized that e-waste, similarly to soils, are heterogeneous and unsaturated matrices at the microbial scale. An average e-waste typically contains a mixture of several different metals (around 57; [37]). As a result, we aimed at taking advantage of the BFI that take place into soils, in particular $\mathrm{FH}$, to trigger biogeochemical processes to both mobilize and immobilize a model metal from e-waste (Figure 1A). As model metal present in e-waste, we selected Cadmium (Cd), as it is a highly toxic nonessential metal [38]. Cd is present in many types of e-waste and is therefore problematic as it often leads to soil and groundwater pollution during landfilling [39]. In e-waste, $\mathrm{Cd}$ is in the range of $180 \mathrm{ppm}$, while precious metals like $\mathrm{Au}$ or $\mathrm{Ag}$ are present between 10 to 1000 and $3000 \mathrm{ppm}$, respectively ([1,2]). However, this varies enormously among e-waste types. As a result, the recovery of precious metals in such matrices strongly relies on the (bio)geochemical behavior of all the elements present in a given e-waste. Precious metals and many heavy metals are nonessential for life. Their toxicity depends on their speciation and the prevailing abiotic condition [38,40]. While $\mathrm{Cd}$ is highly toxic whatever its speciation [41], precious metals exhibit varied levels of toxicity in function of their speciation. Usually, elemental forms are less harmful than ionized species [42,43]. The economic value of $\mathrm{Cd}$ is low and as a result its recovery is not a priority. However, improper e-waste recycling can lead to Cd transfer to soil and groundwater [44]. As a result, during e-waste processing to recover precious metals, the recovery of $\mathrm{Cd}$ is also a critical aspect to take into account. Besides this, by using a highly toxic model metal we assumed that this is a setting that would be initially non-favorable for biological activity. Finding the right conditions allowing biological activity could, therefore, be extrapolated to other less toxic compounds contained in e-waste, such as precious metals for instance.

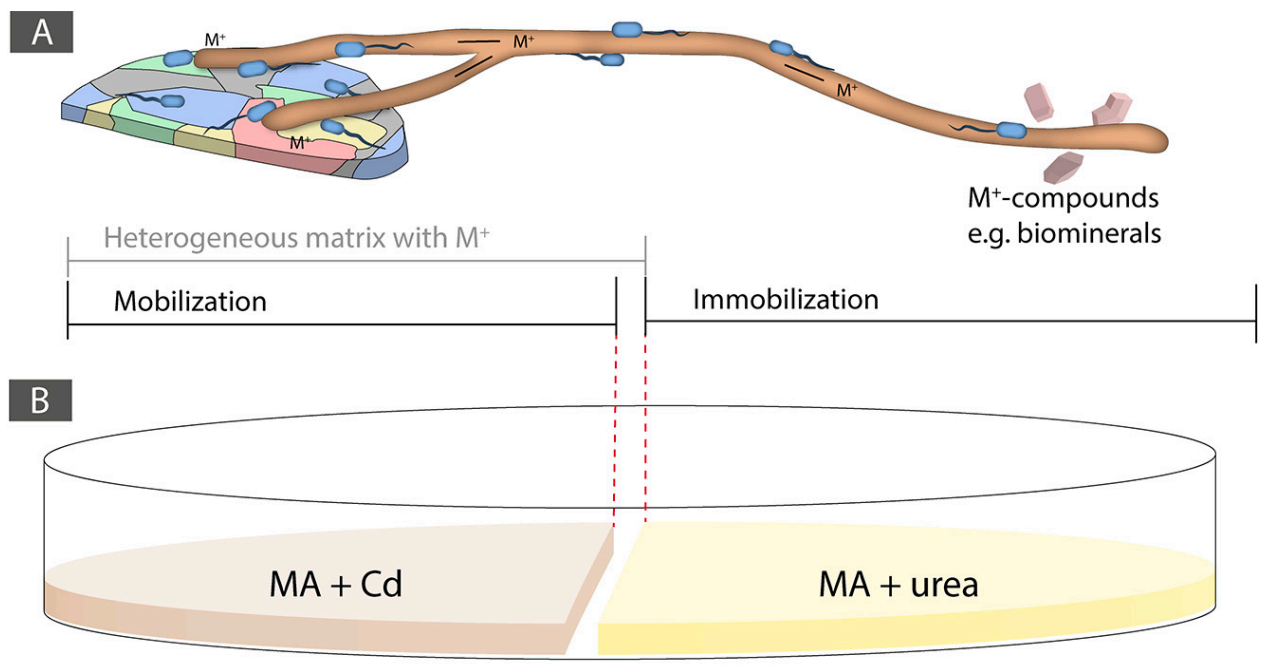

Figure 1. (A) Conceptual design of the approach using bacterial-fungal interactions and fungal highways for the biorecovery of metals in a heterogeneous and unsaturated matrix. On the left-side, a mobilization area is shown consisting of a metal-containing heterogeneous area such as an e-waste and on the right-side is shown an immobilization area where biologically induced mineralization (i.e., biomineralization) can take place for the biorecovery of a metal fraction. (B) Experimental set-up of the Cd mobilization and immobilization Petri dish experiment. 
In recent years, several studies dealt with microbial mechanisms for the biorecovery of metals $[2,8,18,45]$. However, up to now, most of these studies were done in liquid (thus homogeneous) media, where the contact between microbes and metals is amplified. In addition, applications were performed mostly with single bacterial or fungal strains. As a result, this study aims at investigating a solution using BFI and FH for the biorecovery of metals from solid materials in unsaturated conditions. More specifically we investigated whether interacting bacteria and fungi developed metal-tolerance proprieties and cooperative interactions, such as $\mathrm{FH}$, in presence of $\mathrm{Cd}$. For this we selected Cd-tolerant bacterial and fungal strains, either from a Cd-contaminated field site or from our culture collection. Then, we assessed their ability to mobilize $\mathrm{Cd}$ from a culture medium and further to re-immobilize $\mathrm{Cd}$ through biologically induced mineralization (BIM) of $\mathrm{CdCO}_{3}$ as a result of alkalinization linked to ureolysis.

\section{Materials and Methods}

\subsection{Field Sampling}

Selection of the field site to isolate interacting fungal and bacterial strains (thereafter referred to as bacterial-fungal (BF) couples) was performed on the report of naturally Cd-enriched soils at "la Vue des Alpes", canton Neuchâtel, Switzerland. The soils in this area have a mean Cd concentration of $4.58 \mathrm{mg} \mathrm{Cd} / \mathrm{kg}$ soil and maximal Cd concentration of $16.3 \mathrm{mg} \mathrm{Cd} / \mathrm{kg}$ soil [46]. These values largely exceed the official Swiss indicative value for soils fixed at $0.8 \mathrm{mg} \mathrm{Cd} / \mathrm{kg}$ soil [47]. The Cd concentration is the result of the weathering of Cd-enriched carbonate rocks from Middle and Early Late Jurassic and is incorporated in soils after pedogenetic processes. Total Cd concentration rises in the deepest part of the soil but $\mathrm{Cd}$ bioavailability can be higher at the surface as a result of organic acid leaching by plants and microbes [46]. Therefore, BF couples were isolated from the surface of these soils using FH columns as designed by Simon et al. [48]. Both the attracting and the target media consisted of a malt extract ( $12 \mathrm{~g} / \mathrm{L}$; SIOS Home Brewing) and agar ( $15 \mathrm{~g} / \mathrm{L}$; Biolife italiana; MA) medium enriched with $0.05 \mathrm{mM}$ and $0.1 \mathrm{mM} \mathrm{Cd}$ (as cadmium sulfate octahydrate- $\mathrm{CdSO}_{4} \cdot 8 \mathrm{H}_{2} \mathrm{O}$; Sigma-Aldrich, St. Louis, MO, USA) in order to represent the highest and lowest $\mathrm{Cd}$ concentrations measured in Quezada-Hinojosa et al. [36]. Control FH columns without $\mathrm{Cd}$ addition were also used in case the presence of $\mathrm{Cd}$ in the $\mathrm{FH}$ columns prevented microbial growth. A total of $32 \mathrm{FH}$ columns were placed for seven days in three different sites (site $1: 5.3 \mathrm{mg} / \mathrm{kg} \mathrm{Cd}$, site $2: 6.1 \mathrm{mg} / \mathrm{kg} \mathrm{Cd}$ and site 3: $7.3 \mathrm{mg} / \mathrm{kg} \mathrm{Cd}$ ) along the Cd-polluted area. These corresponded to $14 \mathrm{FH}$ columns with a high Cd-concentration ( $0.1 \mathrm{mM} \mathrm{Cd}$; " $\mathrm{b}$ " FH columns), $14 \mathrm{FH}$ columns with a low $\mathrm{Cd}$-concentration ( $0.05 \mathrm{mM} \mathrm{Cd}$; "j" FH columns) and $3 \mathrm{FH}$ control columns ( $0 \mathrm{mM} \mathrm{Cd}$; "r" FH columns). In site 1 (lowest concentration) $3 \mathrm{FH}$ columns of $0.1 \mathrm{mM} \mathrm{Cd}, 3 \mathrm{FH}$ columns of $0.05 \mathrm{mM} \mathrm{Cd}$ and $1 \mathrm{FH}$ control column were placed. Four FH columns of $0.1 \mathrm{mM} \mathrm{Cd}, 4 \mathrm{FH}$ columns of $0.05 \mathrm{mM} \mathrm{Cd}$ and 1 control FH column in the second site were placed in the site with middle Cd concentration (site 2). In the site 3, $7 \mathrm{FH}$ columns of $0.1 \mathrm{mM} \mathrm{Cd}, 7 \mathrm{FH}$ columns of $0.05 \mathrm{mM} \mathrm{Cd}$ and 1 control FH column were placed. More FH columns were used in the third site because of the possible higher selectivity due to the higher $\mathrm{Cd}$ concentration. FH columns were left for seven days in the field. After collecting them from the filed, they were stored for three days at $4{ }^{\circ} \mathrm{C}$ until further processing.

In order to isolate pure fungal and bacterial strains, the target media of each FH column was cut in 4 pieces as described in Simon et al. [48]. From these, 2 pieces were inoculated on a MA medium and the other 2 pieces were immersed in $1 \mathrm{~mL}$ physiologic water $(9 \mathrm{~g} / \mathrm{L} \mathrm{NaCl}$; Sigma-Aldrich) and agitated using a vortex. From the latter solution, $100 \mu \mathrm{L}$ were inoculated on a nutrient broth (8 g/L; Biolife italiana) and agar (NA) medium. MA was enriched with an anti-bacterial solution (chloramphenicol 50 ppm and steptomycin 50 ppm or kanamycin 100 ppm; Sigma-Aldrich), whereas NA media was enriched with the anti-fungal cycloheximide (Sigma-Aldrich) at $1000 \mathrm{ppm}$. Isolated bacteria and fungi were identified using Sanger sequencing of 16S rRNA gene and ITS (ITS 1 and 2 regions including the 5.8S rRNA) PCR products, respectively. The following primer pairs were 
used: (1) for the 16S rRNA gene: Gm3f 5'-AGAGTTTGATC(AC)TGGC-3' and Gm4r 5'-TACCTTGTTA CGACTT-3'; (2) for the ITS 1 and 2 regions: ITS1-F 5'-CTTGGTCATTTAGAGGAAGTAA-3' and ITS4 5'-TCCTCCGCTTATTGATATGC-3'. The kit used for PCR was the Taq DNA Polymerase with Thermopol Buffer (New England, Biolabs Inc., Ipswich, MA, USA). Both PCR were carried out in a $50 \mu \mathrm{L}$ reaction volume including $2 \mu \mathrm{L}$ genomic DNA $(2 \mathrm{ng} / \mu \mathrm{L}), 39.80 \mu \mathrm{L}$ ultrapure water, $5 \mu \mathrm{L}$ of Buffer NEB 10X, $1 \mu \mathrm{L}$ dNTP mix $200 \mu \mathrm{M}$ each, $1 \mu \mathrm{L}$ of each primer ( $0.2 \mu \mathrm{M}$ as final concentration) and $0.2 \mu \mathrm{L}$ Taq polymerase (1.25 units). Amplification of the $16 \mathrm{~S}$ rRNA gene was done using an initial denaturation at $94{ }^{\circ} \mathrm{C}$ for $10 \mathrm{~min}$, followed by 35 cycles of $30 \mathrm{~s}$ at $94{ }^{\circ} \mathrm{C}, 45 \mathrm{~s}$ at $51^{\circ} \mathrm{C}$, and $1 \mathrm{~min}$ at $68^{\circ} \mathrm{C}$ with a final elongation step of $5 \mathrm{~min}$ at $68^{\circ} \mathrm{C}$. Amplification of the ITS rRNA region was done using an initial denaturation at $95^{\circ} \mathrm{C}$ for $5 \mathrm{~min}$, followed by 30 cycles of $30 \mathrm{~s}$ at $95^{\circ} \mathrm{C}, 30 \mathrm{~s}$ at $55^{\circ} \mathrm{C}$, and $1 \mathrm{~min}$ at $68^{\circ} \mathrm{C}$ with a final elongation step of $5 \mathrm{~min}$ at $68^{\circ} \mathrm{C}$. Quantification of DNA was carried out using Qubit fluorometry (Life technologies) and DNA quality was checked using gel electrophoresis on $1.3 \%$ agarose gel from $5 \mu \mathrm{L}$ samples. Samples were sent for Sanger sequencing to GATC-Biotech. Sequences were deposited in GenBank under accession numbers MG874673 and MG872327. Search for similarity against sequences for both markers (16S rRNA gene and ITS region) was performed using BLAST (Basic Local Alignment Search Tool; [49]) and compared to the complete NCBI database

\subsection{Selection of Model Organisms}

Based on a literature review on metal tolerance and resistance by fungi and bacteria, four fungal and two bacterial strains from the culture collection of the Laboratory of Microbiology (University of Neuchâtel) were selected for assessing their tolerance to Cd. Two Ascomycetes were selected: Beauveria brongniartii $[50,51]$ and Trichoderma rossicum. The latter was chosen because of the positive interaction it establishes with some bacterial strains [52]. Two Basidiomycetes were also selected: Armillaria mellea, because of the formation of rhizomorphs, a fungal tissue aiming at resistance and Laccaria bicolor, an ectomychorrhizal fungus, therefore potentially more tolerant to a stress caused by heavy metals [53]. Bacillus weihenstephanensis $11 \mathrm{kri31}$ and Serratia ureilytica Lr 5/4 were selected as model bacterial strains. Both strains were isolated from a geothermal source in Chile [54].

\subsection{Selection of Cd Tolerant Synergistic Bacterial-Fungal Couples}

The aim of this experimental part was to screen for bacterial-fungal (BF) couples with positive interactions in a Cd-enriched medium, hereafter referred to as synergistic BF couples. Four criteria were used to define synergistic BF couples: (1) bacterial and fungal strains had both to grow at all the following Cd concentrations: $0.1 \mathrm{mM}, 0.25 \mathrm{mM}, 0.5 \mathrm{mM}, 0.75 \mathrm{mM}$ and $1 \mathrm{mM}$; (2) one strain should not have an inhibitory effect on the other inoculated strain; (3) the bacterial and the fungal strains should be able to grow in contact; (4) the bacterial strain should use the mycelium of the fungus for dispersal (FH interaction; [31]). The latter criterion was demonstrated by gently streaking an inoculation loop on the fungal mycelium at the greatest distance possible from bacterial inoculation and by using this as inoculum on a NA + cycloheximide medium. Bacterial growth meant that FH were established. The medium used in all of the following experiments was a modified Angle medium, as this medium has been defined to approximate the composition of the soil solution [55]. The addition of a $0.1 \mathrm{M} \mathrm{Cd}$ stock solution prepared from $\mathrm{CdSO}_{4} \cdot 8 \mathrm{H}_{2} \mathrm{O}$ was used to reach the desired final concentration of $\mathrm{Cd}$. All experiments were carried out using single strains (mono-culture controls) and combinations of bacterial-fungal strains (BF couples; co-culture) in order to highlight differences related as a result of BFI.

The BF couples that presented a positive result for each of the four criteria mentioned above were subjected to further experiments to assess growth in each condition (bacteria and fungus alone compared to BF couple, as well as absence and presence of $\mathrm{Cd}$ ). For fungal inoculations, the largest end of a sterile Pasteur pipette was used in order to normalize the biomass inoculated in the center of the culture medium. Bacterial strains were inoculated from a suspension of an overnight culture in nutrient broth (NB) using a microliter syringe (Hamilton). Three drops of $2 \mu \mathrm{L}$ bacterial suspension 
was inoculated (density of the bacterial suspension at $10^{6}$ cells $/ \mathrm{mL}$ ) in three different points around the fungal inoculum. Controls consisting of single bacterial and fungal cultures were also performed in parallel. Fungal biomass was assessed by measuring colony radial growth. The extent of the apical margin of the fungal colony was marked down up to twice a day and measured until the whole Petri dish was colonized. Bacterial biomass was assessed by counting colony forming units (CFU) after full colonization of the Petri dish by the fungus. To measure CFU counts $5 \mathrm{~mL}$ of $0.4 \%$ tween 80 was added on the surface of bacterial-fungal and bacteria-only plates. After $5 \mathrm{~min}$ of handshaking, $1 \mathrm{~mL}$ was collected and used for serial dilutions until $10^{-6}, 10^{-7}, 10^{-8}(n=2) .100 \mu \mathrm{L}$ of these serial dilutions were plated on NA + cycloheximide medium and number of bacterial colonies was counted after 1 day.

\subsection{Cadmium Mobilization Analysis}

To assess if the $\mathrm{Cd}$ contained in the culture medium was mobilized by the synergistic BF couples, scanning electron microscopy (SEM) observations coupled with in situ elemental analysis with Energy dispersive spectroscopy (EDS) were carried out. In order to facilitate the separation of the microbial biomass from the culture medium a cellophane membrane was placed on its surface following the protocol described by Guennoc et al. [56]. Briefly, cellophane pieces of the dimension of the Petri dish were immersed in boiling EDTA $(0.1 \%)$ for $30 \mathrm{~min}$, rinsed with deionized water, and sterilized twice by autoclaving. After growth of the microorganisms, the biomass was sampled from the culture medium by removing the cellophane piece and by cutting out a small fragment to be prepared for SEM observations and analyses. Samples were mounted on double-sided carbon adhesive stubs. Dehydration was performed with a lyophilizer for $4 \mathrm{~h}$ after an initial cooling with liquid nitrogen. The samples on the stubs were coated with gold for $70 \mathrm{~s}$ and kept in a desiccator until further processing. SEM observations were carried out with a Tescan Mira LMU operated at a distance of $1.05 \mathrm{~mm}$, voltage of $7 \mathrm{keV}$ acceleration and a probe current (PC) of 10. Low voltage acceleration was used in order to avoid biomass destruction and the InBeam detector was used. Elemental microanalyses were performed with an EDAX energy-dispersive spectrometer coupled to the SEM at a distance of $22.921 \mathrm{~mm}$, a voltage of $12.5 \mathrm{keV}$ acceleration, and a PC of 4 .

\subsection{Cadmium Immobilization or Biomineralization}

In order to test the ability of the selected BF couples to immobilize Cd trough biologically induced mineralization (BIM), i.e., carbonate biomineralization, both partners of the synergistic BF couples were tested for their ability to hydrolyze urea ( $40 \mathrm{mM}$ urea containing MA medium). The initial $\mathrm{pH}$ of the medium was adjusted to $\mathrm{pH} 5.5$ using sterile $1 \mathrm{M} \mathrm{HCl}$ after autoclaving and phenol red was added as a $\mathrm{pH}$ indicator to demonstrate $\mathrm{pH}$ increase as a result of urea hydrolysis. Once ureolytic activity was confirmed for both partners of a synergistic BF couple, an experiment setting consisting of a two-compartments system was designed. The aim was to first trigger $\mathrm{Cd}$ mobilization through $\mathrm{FH}$ interaction from a $\mathrm{Cd}$ containing medium and then to immobilize $\mathrm{Cd}$ as $\mathrm{CdCO}_{3}$ through BIM in a urea-containing medium. The mobilization area consisted of a MA medium supplemented with $\mathrm{Cd}$ at several concentrations $(0.1,0.25,0.5,0.75$, and $1 \mathrm{mM} \mathrm{Cd}$, and $0 \mathrm{mM}$ control), while the immobilization area consisted of a $40 \mathrm{mM}$ urea-containing MA medium. The two different media were physically separated by a 3-mm wide gap (Figure 1B). The fungal and bacterial inoculations were done simultaneously, a plug of a fresh fungal culture was inoculated in the Cd-containing medium and, at the same time, two $2 \mu \mathrm{L}$ drops of an overnight bacterial-pre-culture in NB were inoculated on the same side between the fungal inoculum and the gap. 


\section{Results}

\subsection{Isolations of Bacterial and Fungal Strains from Cd Contaminated Soil}

Isolation in the field was done between the 23-30 May 2017. All 3 control FH columns (i.e., without $\mathrm{Cd}$ ) were fully colonized. To the contrary, no organisms were isolated in FH columns with the highest Cd-concentration in the target medium (FH columns " $\mathrm{b}$ "; $0.1 \mathrm{mM}$ ). At $0.05 \mathrm{mM}$ Cd-concentration (FH columns " $\mathrm{j}$ "), 7 BF couples were isolated: 2 BF couples from site 1 (lowest Cd concentration among sampling sites; BF couples $1 \mathrm{j} 1$ and $1 \mathrm{j} 2$ ), 4 BF couples from site 2 (middle Cd concentration among sampling sites; BF couples $2 \mathrm{j} 1$ to $2 \mathrm{j} 4$ ) and 1 BF couple from site 3 (highest Cd concentration among sampling sites; BF couple 3j7; Table 1). Bacterial and fungal strains of the two BF couples isolated from site 1 (1j1 and 1j2) grew in mono-culture until $0.25 \mathrm{mM} \mathrm{Cd}$. However, in BF co-cultures, bacteria inhibited fungal growth and, as a result, no FH interaction was observed for both BF couples isolated from site 1 . At site 2 , two BF couples $(2 \mathrm{j} 1$ and $2 \mathrm{j} 4)$ grew well at $0.1 \mathrm{mM} \mathrm{Cd}$, with both contact between bacterial and fungal partners and establishment FH interaction. However, at $0.25 \mathrm{mM} \mathrm{Cd}$ bacterial growth was inhibited as a result of Cd toxicity and no growth was observed from both mono- and co-cultures. A similar result was observed for the bacterial strain of BF couple $2 \mathrm{j} 2$. In addition to this, the bacterial strain of this BF couple inhibited the growth of its fungal partner in the conditions tested and neither contact, nor FH were observed for this BF couple, whatever the Cd concentration. The bacterial and fungal partners of BF couple $2 \mathrm{j} 3$ were in physical contact in non-containing $\mathrm{Cd}$ medium, however no FH interaction was detected. Then, in presence of $\mathrm{Cd}$, the bacterial strain was strongly inhibited by the presence of Cd. Finally, for the BF couple isolated from site 3 (3j7), the fungal strain alone showed normal growth at all Cd-concentrations, i.e., up to $1 \mathrm{mM} \mathrm{Cd}$. The bacterial strain alone grew also at all $\mathrm{Cd}$ concentrations, however it showed reduced growth at $0.75 \mathrm{mM}$ and $1 \mathrm{mM} \mathrm{Cd}$. In addition to this, both partners of the BF couple were in physical contact at all $\mathrm{Cd}$ concentrations tested and $\mathrm{FH}$ interactions were observed at $0.1 \mathrm{mM}, 0.25 \mathrm{mM}$, and $0.5 \mathrm{mM} \mathrm{Cd}$. At higher Cd concentrations, $0.75 \mathrm{mM}$ and $1 \mathrm{mM}$, no FH interaction was observed (Table 2). As a result, BF couple 3j7 was selected as a first possible synergistic BF couple for further experiments. The bacterial and fungal partners of this BF couple were identified as Pseudomonas sp. (98\% similarity) and Boeremia exigua (99\% similarity), respectively. 
Table 1. Summary of the sampling of bacterial-fungal couples using fungal highway (FH) columns at three different sites in Cd-contaminated soils in la "Vue-des-Alpes". $\mathrm{Cd}$ concentration [mg Cd/ $\mathrm{kg}$ soil] at each site was: 5.3 at site 1, 6.1 at site 2, and 7.3 at aite 3. " $\mathrm{j}$ " FH columns contained $0.05 \mathrm{mM} \mathrm{Cd}$ in the target medium, " $\mathrm{b}$ " FH columns contained $0.1 \mathrm{mM} \mathrm{Cd}$ and " $\mathrm{r}$ " FH columns contained no Cd (control FH columns). + stand for growth of a given microbe (either fungi or bacteria) in the target medium and - stand for no growth.

\begin{tabular}{|c|c|c|c|c|c|c|c|c|c|c|}
\hline & $\begin{array}{l}0.05 \mathrm{mM} \mathrm{Cd} \text { "j" } \\
\text { FH Columns }\end{array}$ & Fungi & Bacteria & Couple Name & $\begin{array}{l}0.1 \mathrm{mM} \mathrm{Cd} \text { “b” } \\
\text { FH Columns }\end{array}$ & Fungi & Bacteria & $\begin{array}{l}0 \mathrm{mM} \mathrm{Cd} \text { " } r \text { " } \\
\text { FH Columns }\end{array}$ & Fungi & Bacteria \\
\hline \multirow{3}{*}{$\begin{array}{c}\text { Site } 1 \\
\text { (Low Cd) }\end{array}$} & $\mathrm{j} 1$ & + & + & $1 \mathrm{j} 1$ & $\mathrm{~b} 1$ & - & - & \multirow[t]{3}{*}{ r1 } & \multirow[t]{3}{*}{+} & \multirow[t]{3}{*}{+} \\
\hline & j2 & + & + & $1 \mathrm{j} 2$ & b2 & - & - & & & \\
\hline & j3 & - & - & & b3 & - & - & & & \\
\hline \multirow{4}{*}{$\begin{array}{c}\text { Site } 2 \\
\text { (Middle Cd) }\end{array}$} & j1 & + & + & $2 j 1$ & $\mathrm{~b} 1$ & - & - & \multirow[t]{4}{*}{ r1 } & \multirow[t]{4}{*}{+} & \multirow[t]{4}{*}{+} \\
\hline & j2 & + & + & $2 j 2$ & b2 & - & - & & & \\
\hline & j3 & + & + & $2 j 3$ & b3 & - & - & & & \\
\hline & j4 & + & + & $2 j 4$ & $\mathrm{~b} 4$ & - & - & & & \\
\hline \multirow{7}{*}{$\begin{array}{c}\text { Site } 3 \\
\text { (High Cd) }\end{array}$} & j1 & - & - & & $\mathrm{b} 1$ & - & - & \multirow[t]{3}{*}{$\mathrm{r} 1$} & \multirow[t]{3}{*}{+} & \multirow[t]{3}{*}{+} \\
\hline & $\mathrm{j} 2$ & - & - & & b2 & - & - & & & \\
\hline & j3 & - & - & & b3 & - & - & & & \\
\hline & j4 & - & - & & $\mathrm{b} 4$ & - & - & \multirow[t]{4}{*}{ r2 } & \multirow[t]{4}{*}{+} & \multirow[t]{4}{*}{+} \\
\hline & j5 & - & - & & b5 & & - & & & \\
\hline & j6 & - & - & & b6 & - & - & & & \\
\hline & j7 & + & + & $2 j 7$ & b7 & ND & ND & & & \\
\hline
\end{tabular}


Table 2. Results of the screening to define synergistic bacterial-fungal (BF) couples using bacterial and fungal strains isolated in the field or from the culture collection. Four criteria were assessed: (1) level of Cd tolerance; (2) Bacterial inhibition on fungus; (3) Presence of a physical contact between the fungus and the bacteria; and (4) establishment of fungal highways (FH).

\begin{tabular}{|c|c|c|c|c|c|c|}
\hline & \multicolumn{6}{|c|}{ Criteria } \\
\hline & BF Couple & (1) Cd Tolerance & $\begin{array}{c}\text { (2) Bacterial Inhibition } \\
\text { on Fungus }\end{array}$ & (3) Physical Contact & (4) FH & $\begin{array}{c}\text { Synergistic BF } \\
\text { Couple }\end{array}$ \\
\hline \multirow{7}{*}{$\begin{array}{l}\text { Isolates FH } \\
\text { columns }\end{array}$} & $1 \mathrm{j} 1$ & $0.25 \mathrm{mM}$ & Yes & No & No & No \\
\hline & $1 \mathrm{j} 2$ & $0.25 \mathrm{mM}$ & Yes & No & No & No \\
\hline & $2 j 1$ & $0.25 \mathrm{mM}$ & No & No & No & No \\
\hline & $2 j 2$ & $0.25 \mathrm{mM}$ & Yes & No & No & No \\
\hline & $2 \mathrm{j} 3$ & $0.1 \mathrm{mM}$ & No & No & No & No \\
\hline & $2 \mathrm{j} 4$ & $0.25 \mathrm{mM}$ & No & No & No & No \\
\hline & $3 \mathrm{j} 7$ & $1 \mathrm{mM}$ & Until $0.25 \mathrm{mM} \mathrm{Cd}$ & Yes & Until $0.5 \mathrm{mM} \mathrm{Cd}$ & Yes \\
\hline \multirow{4}{*}{$\begin{array}{l}\text { Strains } \\
\text { culture } \\
\text { collection }\end{array}$} & Be. brongniartii-S. ureilytica Lr 5/4 & $1 \mathrm{mM}$ & Yes & No & No & No \\
\hline & L. bicolor-S. ureilytica Lr 5/4 & $0.25 \mathrm{mM}$ & Yes & No & No & No \\
\hline & A. mellea-S. ureilytica $\operatorname{Lr} 5 / 4$ & - & Yes & No & No & No \\
\hline & T. rossicum-Serratia ureilytica $\operatorname{Lr} 5 / 4$ & $1 \mathrm{mM}$ & In $0 \mathrm{mM} \mathrm{Cd}$ & Yes & Yes & Yes \\
\hline
\end{tabular}




\subsection{Selection from a Culture Collection}

S. ureilytica $\operatorname{Lr} 5 / 4$ showed a high degree of tolerance to Cd with a normal growth up to $1 \mathrm{mM}$ $\mathrm{Cd}$. On the other hand, the growth of $B a$. weihenstephanensis $11 \mathrm{kri3} 1$ was inhibited already at $0.25 \mathrm{mM}$ $\mathrm{Cd}$ concentration and therefore, this strain was not selected for further experiments. T. rossicum and Be. brongniartii grew up to $1 \mathrm{mMCd}$ and colonized an entire mini Petri dish (diameter $4.5 \mathrm{~cm}$ ) in 3 and 5 days, respectively. A. mellea grew until $0.5 \mathrm{mM} \mathrm{Cd}$ but had a slow growth (30 days to colonize an entire mini Petri dish). For this reason, it was not selected for further tests. Finally, L. bicolor was inhibited already at $0.1 \mathrm{mM} \mathrm{Cd}$ and no growth was observed from $0.25 \mathrm{mM} \mathrm{Cd}$ and higher. As a result, this fungal strain was also not selected for further tests.

For BF couple Be. brongniartii-S. ureilytica $\operatorname{Lr} 5 / 4$, a physical contact was observed only in non-Cd containing Angle medium, however without any $\mathrm{FH}$ interaction. In Cd-containing media (from 0.1 to $1 \mathrm{mM}$ Cd concentrations) the bacterial strain inhibited the fungal strain. Moreover, at $0.5 \mathrm{mM}$ $\mathrm{Cd}$ fungal biomass turned yellow. For BF couple T. rossicum-S. ureilytica Lr 5/4, FH interactions were observed despite the initial inhibition of the fungus by the bacteria in non-Cd containing Angle medium. In presence of $\mathrm{Cd}$ the inhibition effect of the bacterium over fungal growth disappeared and the FH interaction persisted at all Cd concentration (Table 2). As a result, this BF couple was selected as a second possible synergistic BF couples.

\subsection{Biomass Assessments of the Synergistic BF Couples}

For the BF couple B. exigua-Pseudomonas sp., in co-cultures containing 0, 0.1, and $0.25 \mathrm{mM} \mathrm{Cd}$ the bacterial strain had an inhibition effect on B. exigua, with the most evident inhibition effect in the $0 \mathrm{mM}$ control plate. At higher $\mathrm{Cd}$ concentrations $(0.5 \mathrm{mM}, 0.75 \mathrm{mM}$ and $1 \mathrm{mM})$ the bacterial inhibition effect was lost (Figure 2A). The FH interaction was present in no-Cd, $0.1 \mathrm{mM}, 0.25 \mathrm{mM}$, and $0.5 \mathrm{mM}$ $\mathrm{Cd}$ concentrations but not at higher concentrations. The CFU numbers of Pseudomonas sp. in single cultures remained constant from 0 to $0.25 \mathrm{mM}$ and then decreased progressively with increasing $\mathrm{Cd}$ concentrations. In co-cultures with the fungal strain, the number of bacterial cells increased at 0.1 and $0.25 \mathrm{mM}$ as compared with the no Cd control. Then, CFU numbers decreased from $0.5 \mathrm{mM}$ and higher (Figures 2B and A1). The radial growth of B. exquia in co-culture was larger at higher $\mathrm{Cd}$ concentrations $(0.5 \mathrm{mM}, 0.75 \mathrm{mM}$ and $1 \mathrm{mM})$ as compared to lower $C d$ concentrations $(0.1 \mathrm{mM}$ and $0.25 \mathrm{mM}$; Figures $2 \mathrm{C}$ and $\mathrm{A} 1)$. In single culture, the radial growth of the fungus was similar over the range of $\mathrm{Cd}$ concentrations (Figures $2 \mathrm{D}$ and $\mathrm{A} 1$ ).

For the BF couple T. rossicum-S. ureilytica $\mathrm{Lr} 5 / 4$ a better tolerance to increasing Cd concentrations was observed in co-cultures as compared to mono-cultures. In no-Cd medium the bacterium inhibited the growth of $T$. rossicum and this effect decreased already at $0.1 \mathrm{mM} \mathrm{Cd}$. At $\mathrm{Cd}$ concentrations higher than $0.25 \mathrm{mM}$, the inhibition effect by the bacteria was not observed (Figure 3A). CFU counts showed that $T$. rossicum did not have an inhibitory effect on S. ureilytica $\mathrm{Lr} 5 / 4$. The number of bacterial cells was higher, or equivalent, in the co-cultures as compared to mono-cultures in presence of $\mathrm{Cd}$ (Figures 3B and A2). At $0 \mathrm{mM} \mathrm{Cd}$, the radial growth of $T$. rossicum alone was larger than in co-culture with S. ureilytica $\mathrm{Lr} 5 / 4$. In presence of $\mathrm{Cd}$ in the medium, T. rossicum showed a higher radial growth in co-culture with S. ureilytica Lr 5/4 (Figure 3C,D and Figure A2). T. rossicum colonized the entire Petri dish and S. ureilytica $\mathrm{Lr} 5 / 4$ was dispersed in the entire plate through $\mathrm{FH}$ interaction. 


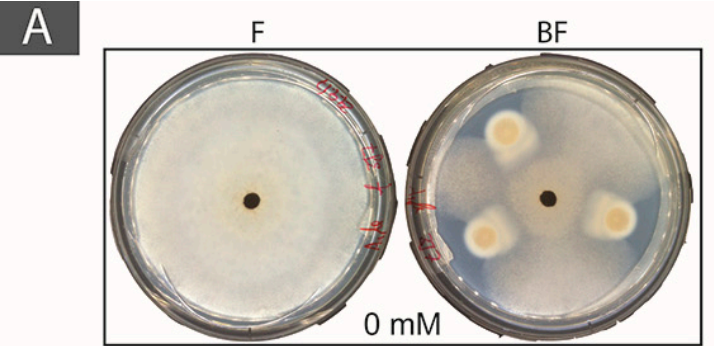

$\mathrm{F}$

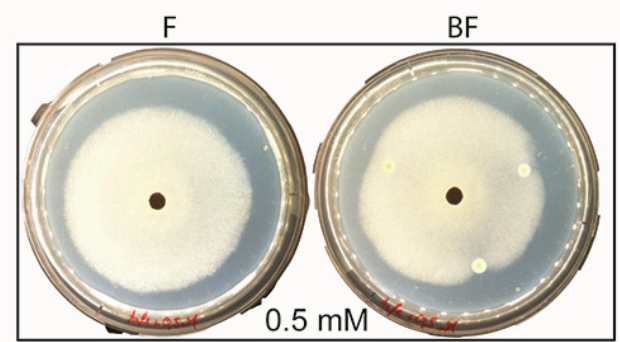

BF

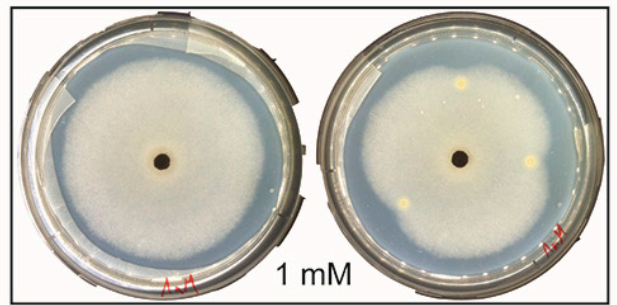

\section{B}

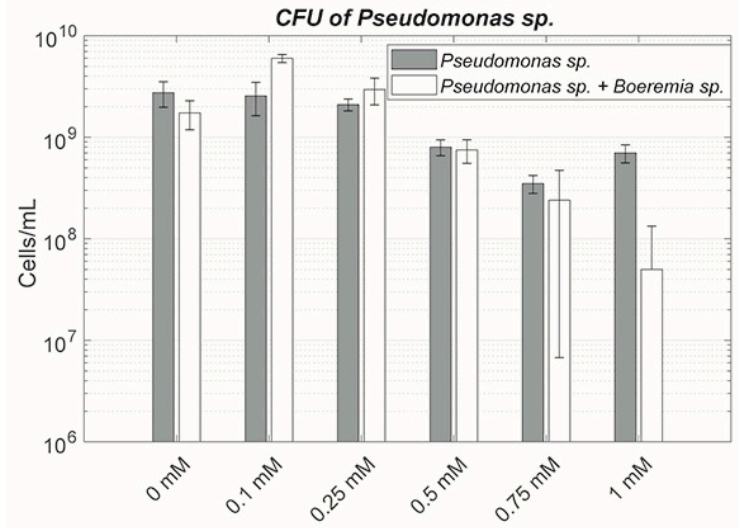

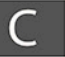

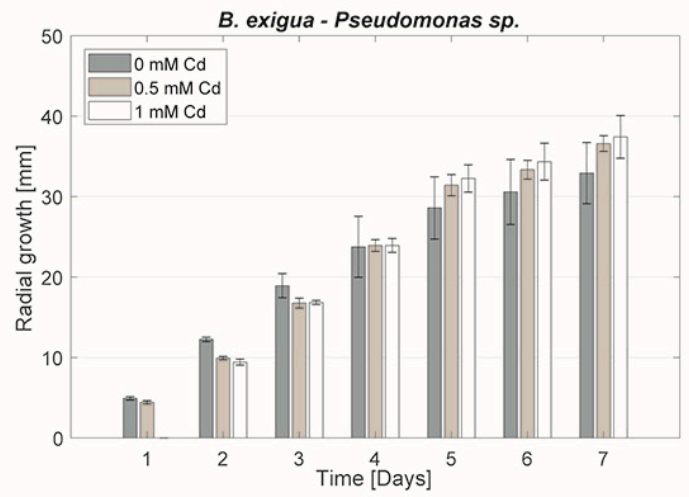

\section{D}

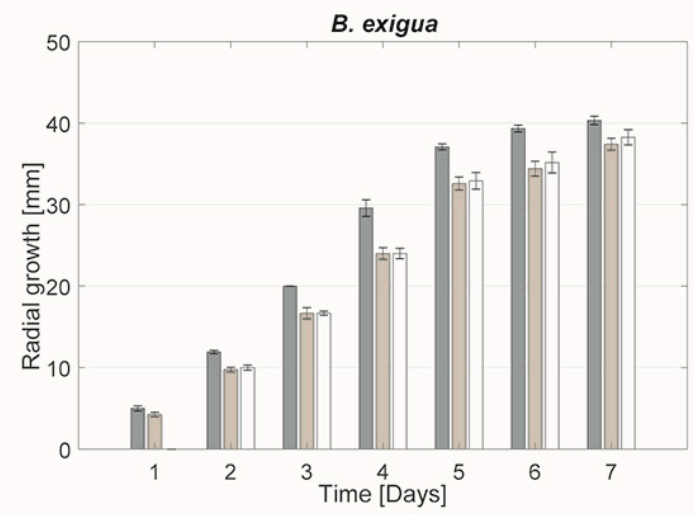

Figure 2. (A) Photographs of mono-cultures of Boeremia exigua (F panels) and co-cultures of B. exigua + Pseudomonas sp. (BF panels) in Angle medium (0 mM Cd) and Cd-containing Angle medium (0.5 and $1 \mathrm{mM} \mathrm{Cd}$ ); (B) Pseudomonas sp. CFU counts in mono-culture and co-culture with B. exigua in Angle medium $(0 \mathrm{mM} \mathrm{Cd}$ ) and Cd-containing Angle medium (0.5 and $1 \mathrm{mM} \mathrm{Cd})$; (C) Radial mycelial growth of B. exigua in co-culture with Pseudomonas sp. in Angle medium (0 mM Cd) and Cd-containing Angle medium ( 0.5 and $1 \mathrm{mM} \mathrm{Cd}$ ); (D) Radial mycelial growth of $B$. exigua in mono-culture in Angle medium $(0 \mathrm{mM} \mathrm{Cd})$ and Cd-containing Angle medium (0.5 and $1 \mathrm{mM} \mathrm{Cd})$. 


\section{A}
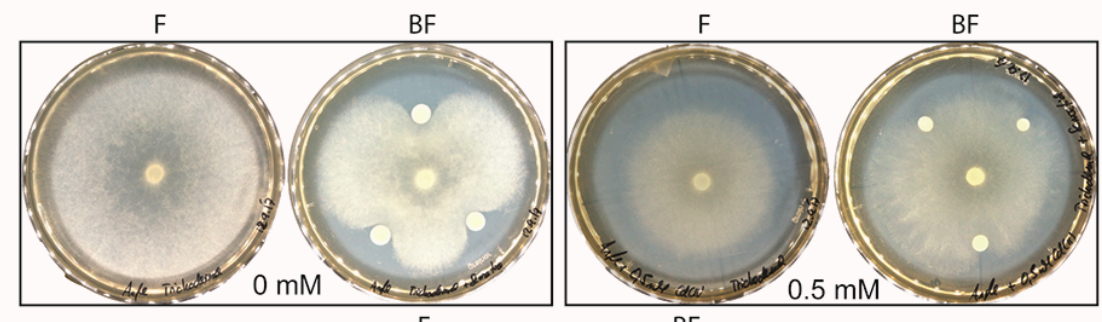

$\mathrm{F}$

$\mathrm{BF}$

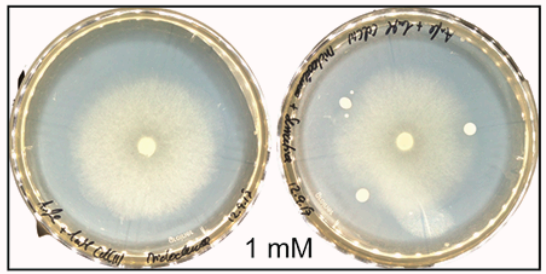

\section{B}

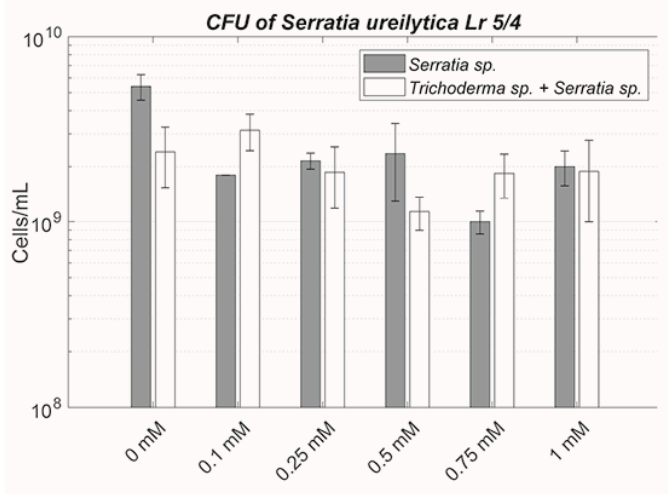

C

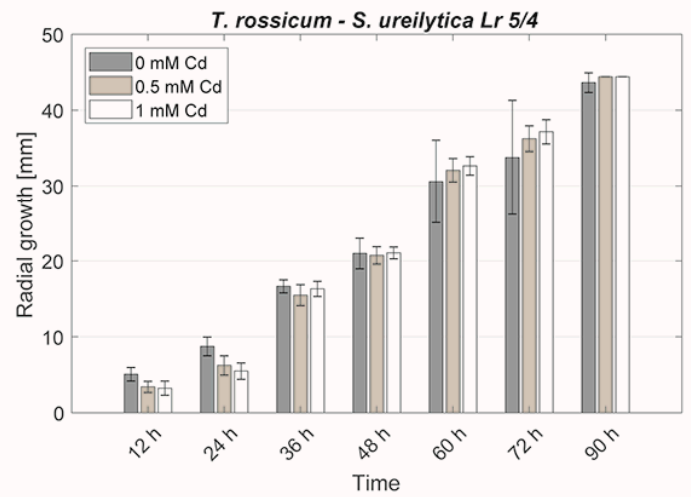

D

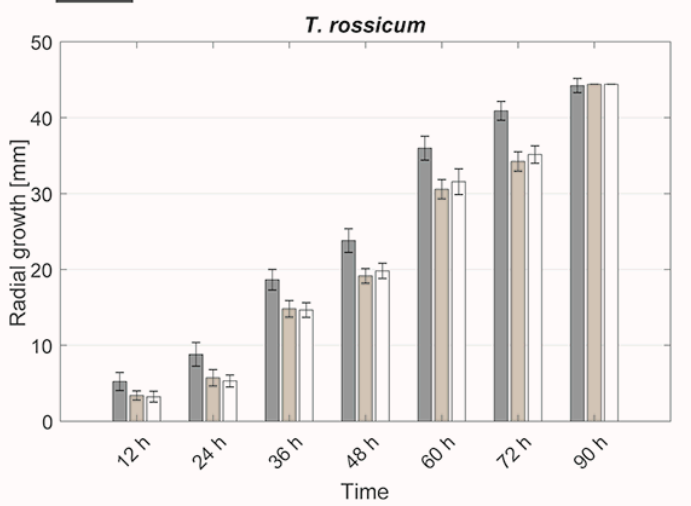

Figure 3. (A) Photographs of mono-cultures of Trichoderma rossicum (F panels) and co-cultures of T. rossicum + Serratia ureilytica Lr 5/4 (BF panels) in Angle medium and Cd-containing Angle medium; (B) S. ureilytica Lr 5/4 CFU counts in mono-culture and co-culture with T. rossicum in Angle medium $(0 \mathrm{mM} \mathrm{Cd})$ and Cd-containing Angle medium (0.5 mM, $1 \mathrm{mM} \mathrm{Cd})$; (C) Radial mycelial growth of T. rossicum in co-culture with S. ureilytica $\mathrm{Lr} 5 / 4$ in Angle medium $(0 \mathrm{mM} \mathrm{Cd})$ and Cd-containing Angle medium (0.5 mM, $1 \mathrm{mM} \mathrm{Cd);} \mathrm{(D)} \mathrm{Radial} \mathrm{mycelial} \mathrm{growth} \mathrm{of} \mathrm{T.} \mathrm{rossicum} \mathrm{in} \mathrm{mono-culture} \mathrm{in} \mathrm{Angle}$ medium $(0 \mathrm{mM} \mathrm{Cd})$ and Cd-containing Angle medium $(0.5 \mathrm{mM}, 1 \mathrm{mM} \mathrm{Cd})$.

\subsection{Cadmium Mobilization Analysis}

Only the couple T. rossicum and S. ureilytica $\operatorname{Lr} 5 / 4$ was assessed for $\mathrm{Cd}$ mobilization as it fulfilled all four criteria (Table 2). SEM images showed that the strains are effectively in physical contact as 
the bacterial strain was observed all along the hyphae of T. rossicum (Figure 4A). The biomass of both strains was covered of small granules (Figure 4A-D). EDS in-situ microanalyses indicated the presence of $\mathrm{Cd}$ associated to the fungal and bacterial biomass for both fungal mono-cultures and BF co-cultures (Figure 4E,F). Seemingly highest amount of $\mathrm{Cd}$ was detected in the biomass of the BF co-cultures in $1 \mathrm{mM}$ Cd concentration, but EDS analyses on non-flat biological samples give only semi-quantitative indications [57].
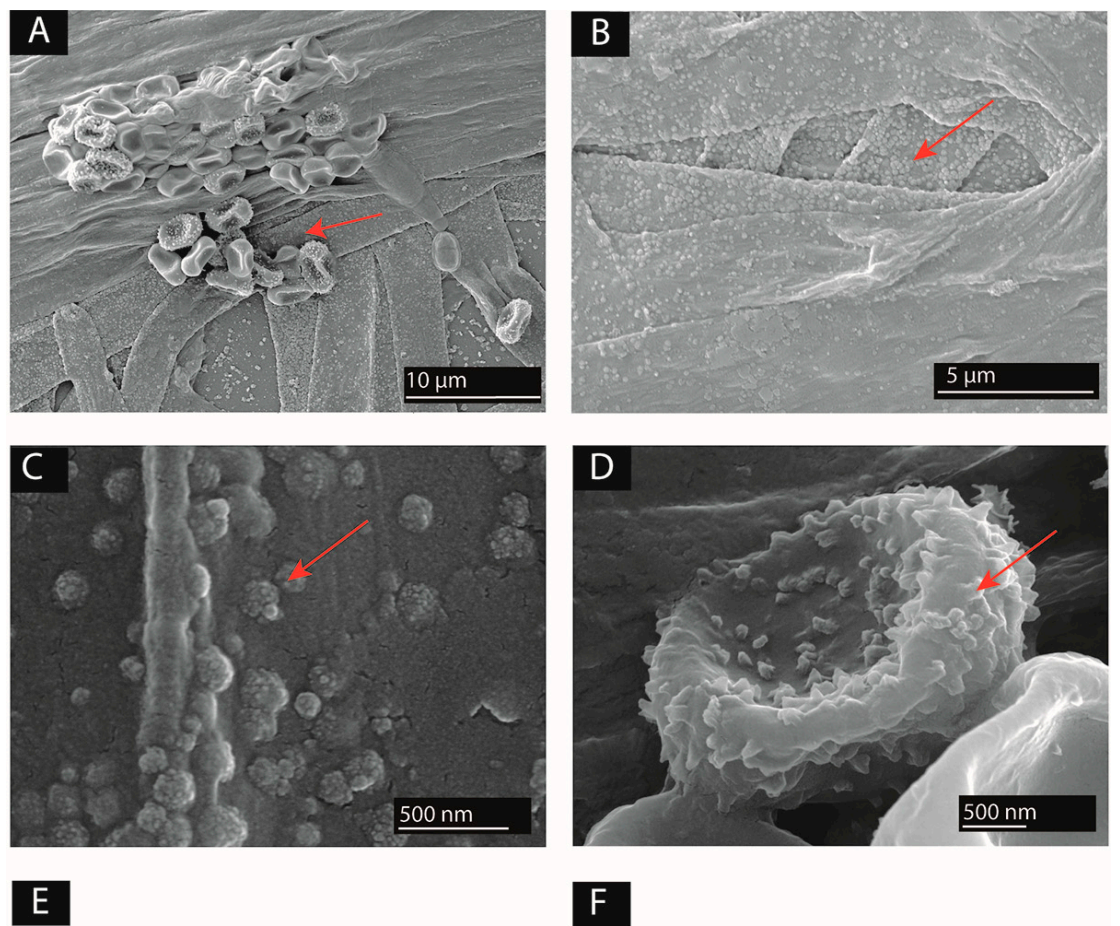

F
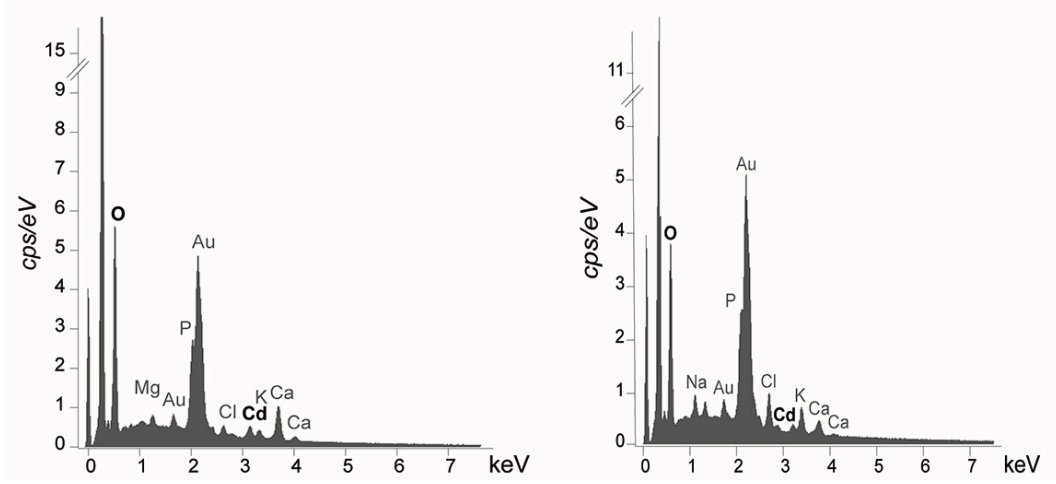

Figure 4. (A-D) Scanning electron microscopy (SEM) images showing the presence of particles associated to the surface of microbial biomass (red arrows) of (A) Trichoderma rossicum and Serratia ureilytica Lr 5/4 in co-culture in $0.5 \mathrm{mM} \mathrm{Cd}$ Angle medium; (B) T. rossicum in mono-culture in $0.5 \mathrm{mM}$ Cd Angle medium; (C) close-up at the hyphal surface of T. rossicum in mono-culture in $0.5 \mathrm{mM}$ Cd Angle medium; (D) close-up at the surface of Serratia ureilytica Lr 5/4 cells grown in $0.5 \mathrm{mM} \mathrm{Cd}$ Angle medium. (E,F) EDS spectra showing the elemental composition of (E) T. rossicum mycelium in mono-culture in $0.5 \mathrm{mM} \mathrm{Cd}$ Angle medium corresponding to image B; (F) the particles at the surface of the hyphae of T. rossicum in mono-culture in $0.5 \mathrm{mM} \mathrm{Cd}$ Angle medium, corresponding to image C.

\subsection{Two-Compartment Cd Mobilization and Immobilization Assay}

Bacterial and fungal strains of both BF couples, B. exigua-Pseudomonas sp. and T. rossicumS. ureilytica Lr 5/4 were all urease-positive. For the BF couple B. exigua and Pseudomonas sp., in all conditions (i.e., without and with $\mathrm{Cd}$ ) the bacteria did not reach the immobilization area, even though 
the fungal strain reached the immobilization area passing the gap after 6 days in the $0 \mathrm{mM}$ control as well as at 0.1 and $0.25 \mathrm{mM} \mathrm{Cd}$ (Table 3). For the other conditions, the fungal strain was inhibited by $\mathrm{Cd}$ toxicity. The hyphae grew inside the agar up to 0.5 until $1 \mathrm{mM} \mathrm{Cd}$ and also did not reach the immobilization area (Figures 5A and A3). For the BF couple T. rossicum and S. ureilytica Lr 5/4, both partners grew and passed the physical separation reaching the urea medium up to $0.5 \mathrm{mM} \mathrm{Cd}$ concentration (Table 3). Both bacterial-fungal partners took 2-5 days before passing the gap and alkalinizing the immobilization area. At 0.75 and $1 \mathrm{mM} \mathrm{Cd}$, the fungal strain was inhibited and the hyphae grew inside the agar resulting in lower fungal growth as compared to the other conditions (Figures 5B and A3). At 0.75 and $1 \mathrm{mM} \mathrm{Cd,} \mathrm{T.} \mathrm{rossicum} \mathrm{needed} \mathrm{20-25} \mathrm{days} \mathrm{before} \mathrm{passing} \mathrm{the} \mathrm{gap,} \mathrm{but}$ the bacteria was not observed after the gap at that time. Finally, we suspected that the concomitant presence of urea increased $\mathrm{Cd}$ toxicity, as B. exigua hyphae melanized in all tested conditions and T. rossicum had a very slow growth as compared to other conditions (Figures 5 and A3).

Table 3. Results of the Cd mobilization and immobilization experiment in two-compartments systems with the two synergistic couples (B. exigua + Pseudomonas sp. and T. rossicum and S. ureilytica $\mathrm{Lr}$ 5/4) showing at each $\mathrm{Cd}$ concentration assessed whether (1) the fungus reached the immobilization area, (2) bacteria used fungal highways to reach the immobilization area, and (3) the $\mathrm{pH}$ increased in the immobilization area.

\begin{tabular}{|c|c|c|c|c|}
\hline Bacterial-Fungal Couple & $\begin{array}{l}\text { Cd Concentration } \\
(\mathrm{mM})\end{array}$ & $\begin{array}{c}\text { Presence of Fungus } \\
\text { behind Gap }\end{array}$ & $\begin{array}{c}\text { Presence of Bacteria } \\
\text { behind Gap }\end{array}$ & $\begin{array}{c}\text { Alkalinization of } \\
\text { Urea Medium }\end{array}$ \\
\hline \multirow{6}{*}{ B. exigua-Peusdomonas sp. } & 0 & Yes & No & Yes \\
\hline & 0.1 & Yes & No & Yes \\
\hline & 0.25 & Yes & No & Yes \\
\hline & 0.5 & No & No & No \\
\hline & 0.75 & No & No & No \\
\hline & 1 & No & No & No \\
\hline \multirow{6}{*}{ T. rossicum-S. ureilytica $\operatorname{Lr} 5 / 4$} & 0 & Yes & Yes & Yes \\
\hline & 0.1 & Yes & Yes & Yes \\
\hline & 0.25 & Yes & Yes & Yes \\
\hline & 0.5 & Yes & Yes & Yes \\
\hline & 0.75 & Yes & No & Yes \\
\hline & 1 & No & No & No \\
\hline
\end{tabular}

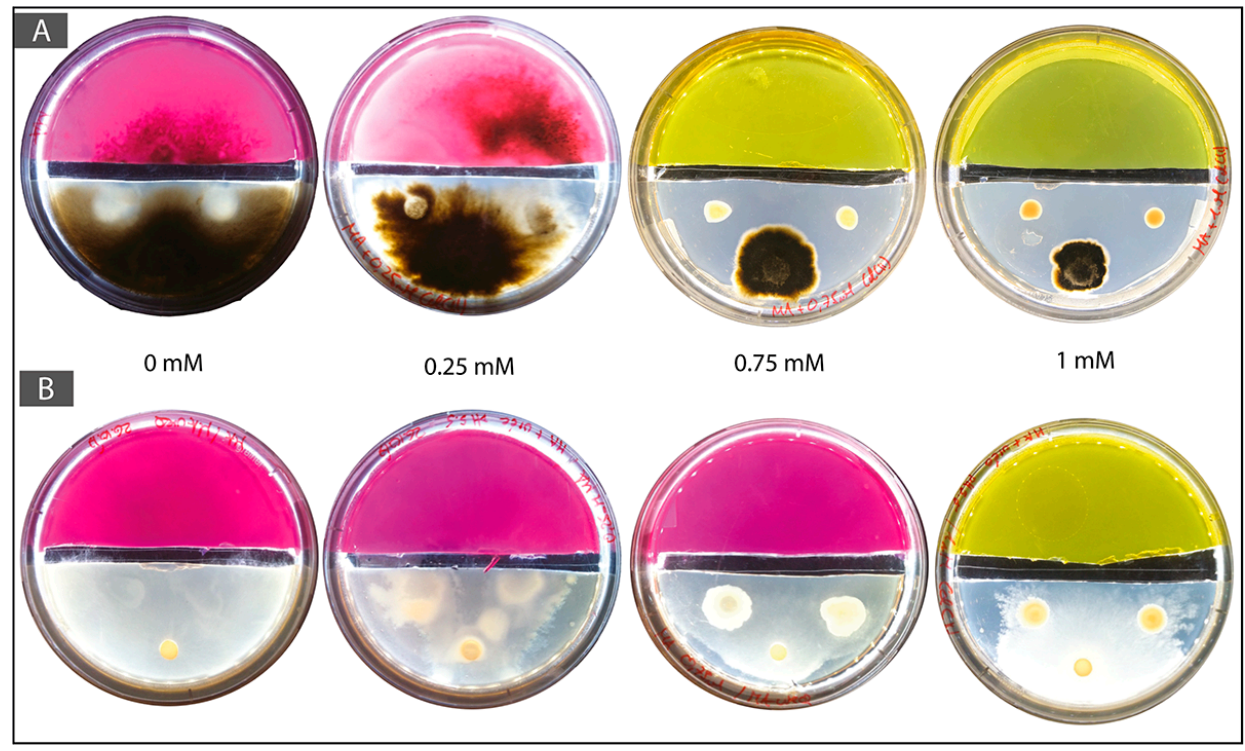

Figure 5. Experimental setting consisting of two-compartment systems in Petri dishes with a mobilization area (bottom part containing MA and Cd; $0 \mathrm{mM}$ control and 0.5, 0.75, and $1 \mathrm{mM} \mathrm{Cd}$ ) and an immobilization area (top colored part containing $\mathrm{MA}, 40 \mathrm{mM}$ urea, and phenol red as $\mathrm{pH}$ indicator). Co-cultures of (A) B. exigua and Pseudomonas sp. (B) T. rossicum and S. ureilytica Lr 5/4. 


\section{Discussion}

This study aimed first at investigating whether BF couples were more tolerant to $\mathrm{Cd}$ as compared to the strains cultured alone. Bacterial and fungal strains isolated from Cd-contaminated sites with a specific device aiming at isolating FH-interacting partners and strains from the culture collection of the laboratory were screened for $\mathrm{Cd}$ tolerance in mono- and co-cultures. BF couples that were able to tolerate $\mathrm{Cd}$ concentrations up to $1 \mathrm{mM}$ and did not inhibit each other in these conditions. Moreover, the strains were able to establish FH interactions were defined as synergistic BF couples. These BF couples were then used to assess if they could first mobilize $\mathrm{Cd}$ from a matrix and then re-immobilize this $\mathrm{Cd}$ as a biomineral.

The FH columns described in Simon et al. [48] allowed for the isolation of several bacterial and fungal strains directly from a Cd-contaminated soil. During the field sampling the Cd-containing target-media of the FH columns permitted to isolate Cd-tolerant bacterial and fungal strains showing the good performance of the isolation device. Indeed, both bacterial and fungal strains were present on the target medium of the FH columns. More microorganisms were detected in FH columns without $\mathrm{Cd}$ (control columns) as compared to the Cd-containing FH columns. No microorganisms could be isolated with the FH columns containing $0.1 \mathrm{mM} \mathrm{Cd}$ (highest Cd-concentration), while several bacterial and fungal strains were isolated from the FH columns containing $0.05 \mathrm{mM} \mathrm{Cd}$ (lowest Cd concentration). After isolation, two fungal strains and one bacterial strain were able to grow up to $1 \mathrm{mM} \mathrm{Cd}$. This shows that in soils with high Cd concentration, such as in "la Vue-des-Alpes", Cd-tolerant microorganisms are present and can be cultured. However, this tolerance could not be extended to higher $\mathrm{Cd}$ concentrations for all the isolated strains. Nevertheless, isolations in metal-contaminated sites seem to be an effective way to collect microorganisms presenting metal tolerance and/or resistance mechanisms as demonstrated in this study and also by several other studies [58-62]. As a further example, a fungal strain that accumulates dysprosium (Dy), a rare earth element, could be isolated from an acidic environment containing high concentration of heavy metals [63]. In this study however, the novelty is that metal-tolerant interacting bacterial and fungal species could be isolated concomitantly. Regarding the level of metal tolerance, contradicting evidence is discussed in the literature. Several researchers found that there is no difference in metal tolerance between isolates from metal-polluted sites compared to those from no-polluted sites. For example, Blaudez et al. [64] showed that there is no difference in metal tolerance between ectomycorrhizal fungi from a polluted soil and from a non-polluted soil. Jones and Hutchinson [65] had similar results regarding $\mathrm{Ni}$ and $\mathrm{Cu}$ bioremediation mechanisms. However, Egerton-Warburton and Griffin [59] claimed that strains isolated from metal contaminated soils where more Al-tolerant than strains from less polluted sites.

One striking aspect of the BF couple isolation is that the FH column device was designed to isolate bacterial-fungal couples that present the FH interaction [48]. Despite this, passing from soil to isolation in Petri dishes averted the FH mechanism. For each isolated couple, FH bacterial dispersal should be observed, and this was not the case in three BF couples out of seven. Finally, only one couple of the seven couples retrieved with FH columns respected all criteria summarized in Table 2 and this was the case only up to $0.5 \mathrm{mM} \mathrm{Cd}$. This might be a result of the fact that the culture medium used during the screening phase in the laboratory with the isolated strains was the Angle medium [55], while the target medium of the FH columns contained MA. Angle medium was chosen for its similarity with the average soil composition, however it seems that the behavior of several organisms changed from the soil to the FH column device (MA culture medium) and further to Petri dish experiments with Angle medium. Therefore, the transition to artificial and less complex culture media as compared to the natural conditions can lead to major changes in the behavior of the isolated microorganisms [66]. Overall, these results show that there are inherent limits to a culture-dependent approach, as it is well known that only a minor fraction of microorganisms is prone to cultivation [21]. However, in the context of metal-contaminated soils, it was demonstrated that a culture-dependent approach was effective at highlighting the physiological 
adaptation of bacteria to metal concentrations [67]. As a result, even though isolation biases exist in culture-dependent approaches, screening metal-contaminated environments for metal-tolerant microorganisms is worthwhile. In this study, this has allowed isolation of one BF couple presenting $\mathrm{Cd}$ tolerance and the ability to establish FH.

First planned as a back-up to the isolation phase with FH columns of this study, the screening of microorganisms from the bacterial and fungal strain collection of the laboratory allowed to highlight one very effective synergistic BF couple: S. ureilytica Lr 5/4 and T. rossicum. The ability of Trichoderma species to tolerate heavy metals was also described by Nomgmaithem et al. [61]. However, these authors suggest that, even though these fungi seem to be metal tolerant, in Cd-contaminated soil their population dynamics may be affected through reduced sporulation. This was also observed in this study, as T. rossicum did not sporulate anymore at $0.5 \mathrm{mM} \mathrm{Cd}$. However, for an effective FH interaction, sporulation is not a required aspect. In this study, an important aspect was the effect on mycelial growth and it was shown that $T$. rossicum mycelial growth was not negatively affected in presence of Cd and S. ureilytica Lr 5/4.

The screening of several BF couples (either from environmental isolates or from the laboratory collection) intended to define at least one synergistic BF couple respecting the four criteria described in material and methods and in Table 2. A first couple was defined from the isolations with FH columns consisting in B. exigua and Pseudomonas sp. The radial growth of the fungus increased with increasing $\mathrm{Cd}$ concentrations. However, this could be an effect of $\mathrm{Cd}$ toxicity with the fungus trying to escape the metal stress by enhancing apical growth as compared to branch formation [68]. Even though this BF couple respected most of the four criteria, it was discarded for further experiments as Cd concentrations higher than $0.5 \mathrm{mM}$ prevented the establishment of FH. T. rossicum and S. ureilytica $\mathrm{Lr}$ $5 / 4$ was the second couple selected. Both microorganisms come from the laboratory collection. While T. rossicum was isolated from a tropical soil with a device similar to FH columns [52], S. ureilytica Lr 5/4 was isolated from a geothermal site [54] and metal tolerance could be expected. In medium without $\mathrm{Cd}$ S. ureilytica $\mathrm{Lr} 5 / 4$ inhibited the growth of T. rossicum, but in Cd-containing media (from $0.1 \mathrm{mM}$ up to $1 \mathrm{mM} \mathrm{Cd}$ ) this inhibitory effect disappeared. The radial growth of $T$. rossicum was increased in presence of S. ureilytica $\operatorname{Lr} 5 / 4$ as compared to a mono-culture (Figure 3). This result suggests that $T$. rossicum was more tolerant to $\mathrm{Cd}$ in presence of $S$. ureliytica $\mathrm{Lr} 5 / 4$. Conversely, the CFU count of the bacterial strain in mono-culture and in co-culture did not show the same stimulated growth effect than for the fungal strain. Bacterial CFU numbers remained in the same range regardless $\mathrm{Cd}$ concentration and no inhibition effect due to the presence of T. rossicum was observed. However, similarly to B. exigua, it cannot be ruled out that the higher radial growth of T. rossicum in presence of $\mathrm{Cd}$ (and bacteria) is a response to stress. Despite this, the fact that $\mathrm{FH}$ were established and effective at all $\mathrm{Cd}$ concentrations and that no inhibition effect between both partners was observed are the most important regarding the aims of this study, that is to harness biogeochemical active BF couples. Therefore, it can still be concluded that this BF couple is synergistic under a biogeochemical aspect (that is $\mathrm{Cd}$ tolerance in this case), as both organisms seem to benefit from their reciprocal growth in presence of $\mathrm{Cd}$.

The ability to mobilize $\mathrm{Cd}$ from a culture medium was assessed for the BF couple T. rossicumS. ureilytica Lr 5/4. SEM images and EDS elemental microanalyses showed the presence of small particles containing $\mathrm{Cd}$ linked to the fungal and bacterial biomass. While this $\mathrm{Cd}$ could also be present below the analyzed biomass and thus not directly linked to the biomass, it suggests that $\mathrm{Cd}$ present in the medium was mobilized and further immobilized, possibly through adsorption (i.e., biosorption) but also as minute biominerals present at the outer cell surfaces (Figure 4). The main functional group responsible for cation biosorption (which can eventually also lead to biomineralization) can be hydroxyls, carbonyls, corboxyl, sulfonates, amides, imidazoles, phosphonate and phosphodiester groups [69,70]. Some of those have been described in Trichoderma spp. [61]. For the investigation of particular metal-microbe interactions, understanding the form and which speciation of given metal is crucial. In the case of $T$. rossicum, there was evidences that when Cd-concentration increased, fungal growth in mono-culture decreased. Regarding S. ureilytica $\mathrm{Lr} 5 / 4$ the metal concentration did not 
impaired its growth (in the range of Cd-concentration investigated). This result suggests that $\mathrm{Cd}$ bioavailability increased along with increasing amount of Cd-stock solution added in the media. Despite this, the precise amount of Cd bioavailability should still be assessed. The concentration of a toxic metal in the medium can vary because of the physicochemical formation of metal-precipitates. Indeed, complexation between metal cations such as $\mathrm{Cd}$ and anions present in the medium may occur. Similarly, leaching can alter metal bioavailability in the medium. Shuttleworth and Unz [71] assumed that only free metal ions are available for binding to the biomass of Thiothrix strain A1 (a filamentous bacterium). Moreover, Hughes and Poole [72] highlighted that it is important to assess the exact metal concentration in the growth medium before demonstrating that an organism is highly tolerant to a given toxic metal. Similarly, TEM images are crucial for investigating microbe-metal interactions. This kind of images can reveal where the metal is actually located in regard to the microbial cell (e.g., metal bound to the cell wall or precipitated outside the cell).

The ability to immobilize $\mathrm{Cd}$ as $\mathrm{CdCO}_{3}$ by induced biomineralization, after its mobilization from a Cd-containing medium, was observed for the two BF couples T. rossicum-S. ureilytica Lr 5/4 and B. exigua-Pseudomonas sp. The aim was to assess whether this mechanism can be used to recover metals in the form of biominerals. Urea hydrolysis and subsequent alkalinization was used to induce $\mathrm{CdCO}_{3}$ biomineralization. All four strains from the two BF couples were confirmed as urease-producers and were thus able to increase the $\mathrm{pH}$ of the culture medium. Several studies [73-75] showed that urease-positive microbes can have an important role in BIM of metal- $\mathrm{CO}_{3}$. For instance, in an urea-containing medium, Neurospora crassa [75] can precipitate metal-carbonates (e.g., $\mathrm{CdCO}_{3}$ ), representing a way to immobilize toxic metals. Consequently, the experimental design tested in this study consisted of a mobilization area containing $\mathrm{Cd}$ and an immobilization area containing urea, where $\mathrm{CdCO}_{3}$ could be formed. Both fungal and bacterial partners could grow from the mobilization area. However, in the BF couple B. exigua-Pseudomonas sp., no FH was established allowing bacteria to reach the immobilization area. For the BF couple T. rossicum-S. ureilytica Lr 5/4, FH were established until $0.5 \mathrm{mM}$. But despite the fact that both the bacterial and the fungal strains were able to hydrolyze urea, no evidence of any $\mathrm{CdCO}_{3}$ biomineralization was observed. As a matter of fact, a major limitation arose in this mobilization-immobilization experiment. The concomitant presence of $\mathrm{Cd}$ and urea seemed to be negative for the growth of both fungi. At high Cd concentrations (0.75 and $1 \mathrm{mM})$, T. rossicum had a slower growth as compared to what was observed without urea (Figures 5 and A2) and the hyphae grew inside the solid media avoiding the contact with the atmosphere of the Petri dish. B. exigua, showed a strong melanization in these conditions. Melanization in fungi is a typical stress response [76] and, has been mentioned to be involved in metal biosorption as a strategy to immobilize toxic metals $[77,78]$. All four strains of the two BFI couples were confirmed as urea-positive and no inhibition effect was present in urea-containing media. On the other hand, in Cd only containing media there was no inhibition effect on the fungal growth as prominent as those observed in the concomitant presence of both $\mathrm{Cd}$ and urea. Therefore, this suggests that the inhibiting effect observed in the mobilization-immobilization experiment is a consequence of the interaction between urea and $\mathrm{Cd}$ in plates. Most likely, this was a $\mathrm{pH}$ effect resulting from urea transformation in $\mathrm{NH}_{4}{ }^{+}$and $\mathrm{NH}_{3}$ and further to their dissolution in an aqueous phase leading to alkalinization. Several studies discuss metal tolerance as a function of $\mathrm{pH}$, however with contrasting observations. Pons and Fusté [79] mentioned that the uptake of uranium was higher at $\mathrm{pH}$ close to 4 in liquid media. In contrast, De Rome and Gadd [80] showed that at lower $\mathrm{pH}$ the capacity of fungal biomass to bind metals such $\mathrm{Cd}$, $\mathrm{Zn}$ and $\mathrm{Cu}$ declines. Indeed, at low $\mathrm{pH}$, there is a competition between hydrogen ions and metal ions for sorption site at the microbial surface [58]. As a matter of fact, in preliminary experiments with media containing urea and $\mathrm{Cd}$ and with an un-controlled $\mathrm{pH}$ (around 7), the growth of T. rossicum was strongly inhibited. Then, when controlling the $\mathrm{pH}$ of the medium to 5.5, the growth of T. rossicum was stimulated. The fungus was able to colonize the entire Petri dish and exhibited a normal growth at the surface of the agar. This points to the fact that at $\mathrm{pH}$ above 7, Cd gets more toxic for T. rossicum. As a result, an applied design to immobilize $\mathrm{Cd}$ as an induced carbonate biomineral has to trigger 
another mechanism than alkalinization. Biomineralization of $\mathrm{CdCO}_{3}$ as in $\mathrm{Li}$ et al. [75] with Neurospora crassa cannot be trigged with the selected organisms in this study due to the negative effect of the concomitant presence of $\mathrm{Cd}$ and urea.

In current biometallurgical approaches, bioleaching is the most used process and consists in a mobilization mechanism as the solubility of the metal is increased. The second most used process is biosorption, which consists in an immobilization mechanism, as the solubility of the metal is decreased to lead to its recovery. However, both processes are not used together in a common commercial process, meaning for instance that in bioleaching processes metal immobilization still relies on physicochemical approaches. In this study, the experimental design consisting of a compartmented setting with a mobilization and an immobilization area separated by an air gap to mimic heterogeneity confirmed the possibility to apply the FH interaction for an applied biorecovery design to recover metals from e-waste. The explorative and the exploitative propriety of the fungus permitted the bacterial strain to disperse trough the air-filled gap. The utilization of a fungal strain as a vector for bacterial dispersion on a heterogenic matrix seems to be an effective tool to be harnessed in the biotechnology field of metal biorecovery and bioremediation of metal-polluted matrices. The appropriate conditions to trigger $\mathrm{Cd}$ immobilization, either through biosorption or biomineralization still need to be defined though.

\section{Conclusions}

The aim of this study was to assess whether synergistic BFI (in terms of biogeochemistry and coexistence) could be applied for the biorecovery of $\mathrm{Cd}$ from e-waste. The choice of using a BF consortium is a consequence of the heterogeneous nature of the e-waste matrix that is akin to soils. In a heterogenic and unsaturated matrix, bacteria cannot freely disperse and thus cannot entirely interact with its components. However, this limitation can be bypassed by applying the explorative strategy of fungi linked to the FH interaction. The initial experimental design was, therefore, conceived to mimic this heterogeneity with a mobilization area where $\mathrm{Cd}$ could be mobilized and translocated by the fungal and bacterial partners and an immobilization area where $\mathrm{Cd}$ could be released and biomineralized under a $\mathrm{CdCO}_{3}$ form. Unfortunately, toxicity of $\mathrm{Cd}$ was higher as a result of alkalinization. In order to fully understand the mechanism of metal interaction and tolerance in the selected microorganisms, further analyses are required. Knowing which tolerance mechanisms the microorganisms are using is important for the design of an experimental and/or applied procedure. If biomineralization can be induced, the medium of the immobilization area could be removed for the recovery of the metal of interest. If the metal is taken up by the biomass and no bioprecipitation can be induced, the recovery of metal could be done directly through biomass harvesting. Nevertheless, the results of this study offer an encouraging perspective for the use of microbial consortium in metal biorecovery. One synergistic $\mathrm{BF}$ couple with biogeochemical ability towards $\mathrm{Cd}$ could be highlighted: the two organisms together are more tolerant to $\mathrm{Cd}$ than the organisms alone and, in presence of $\mathrm{Cd}$, the mycelial network of the fungus was used as a vector by the bacteria to disperse in a heterogeneous matrix. Therefore, harnessing interacting microbes as reactors in urban mining thanks to their ability to mobilize and immobilize toxic metals may be an ecological, economical, and ethical strategy for the biorecovery of metals in e-waste.

Acknowledgments: The authors would like to thank: The "Fondation Pierre Mercier pour la Science" for funding, Pilar Junier for fruitful discussions, Andrej Al-Dourobi and Céline Vallotton for technical assistance during laboratory experiments, Pierre Vonlanthen for assistance in using scanning electron microscopy, Fabio Palmieri and Guillaume Cailleau for help in designing figures.

Author Contributions: Geremia Losa and Saskia Bindschedler designed the experiments and wrote the manuscript. Geremia Losa performed the experiments.

Conflicts of Interest: The authors declare no conflict of interest. 


\section{Appendix}

\section{A}
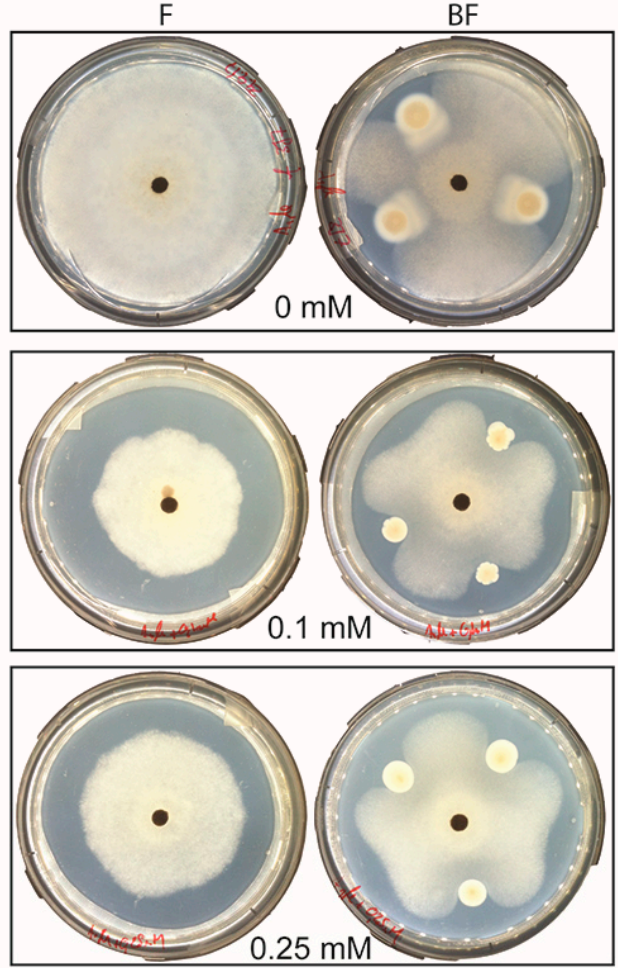

\section{B}

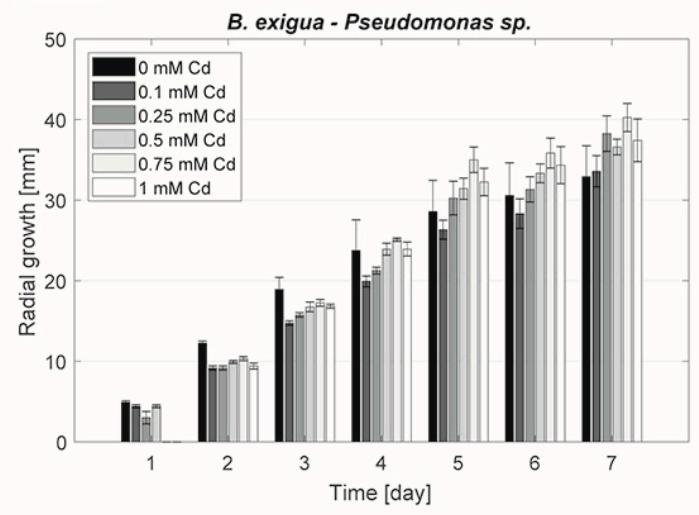

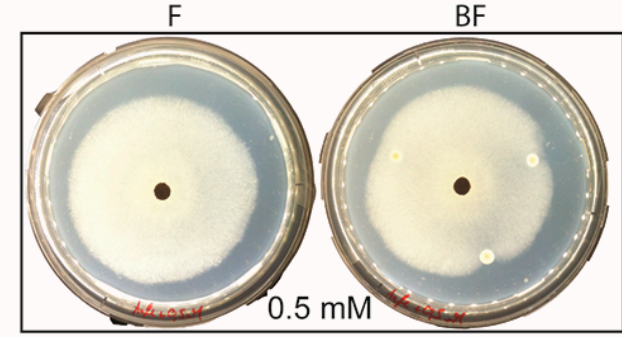
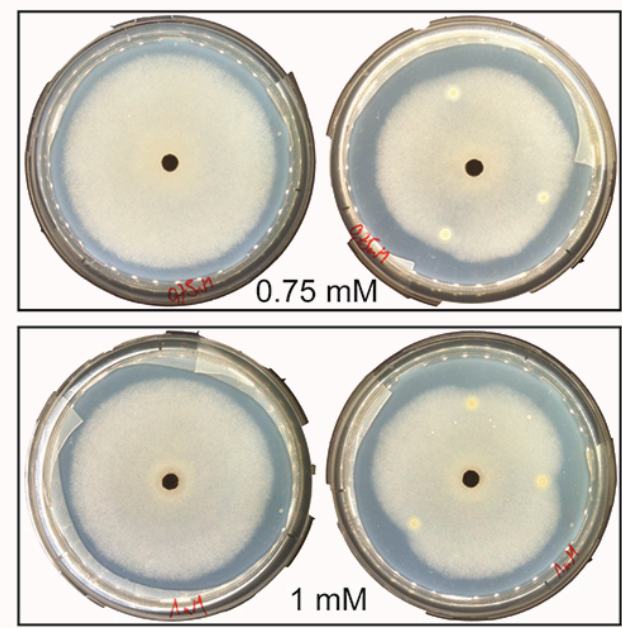

C

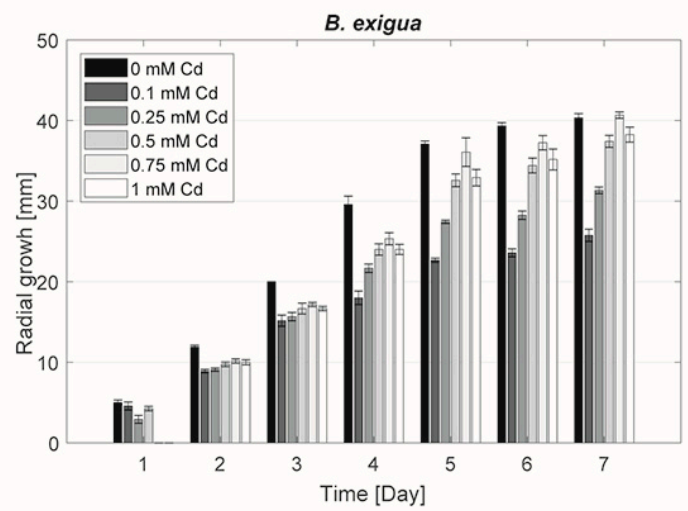

Figure A1. (A) Photographs of mono-cultures of Boeremia exigua (F panels) and co-cultures of B. exigua + Pseudomonas sp. (BF panels) in Angle medium (0 mM Cd) and Cd-containing Angle medium (0.1, $0.25,0.5,0.75$, and $1 \mathrm{mM} \mathrm{Cd}$ ); (B) Radial mycelial growth of B. exigua in co-culture with Pseudomonas sp. in Angle medium (0 mM Cd) and Cd-containing Angle medium (0.5 and $1 \mathrm{mM} \mathrm{Cd}$ ); (C) Radial mycelial growth of B. exigua in mono-culture in Angle medium $(0 \mathrm{mM} \mathrm{Cd})$ and Cd-containing Angle medium $(0.1,0.25,0.5,0.75$, and $1 \mathrm{mM} \mathrm{Cd})$. 
A
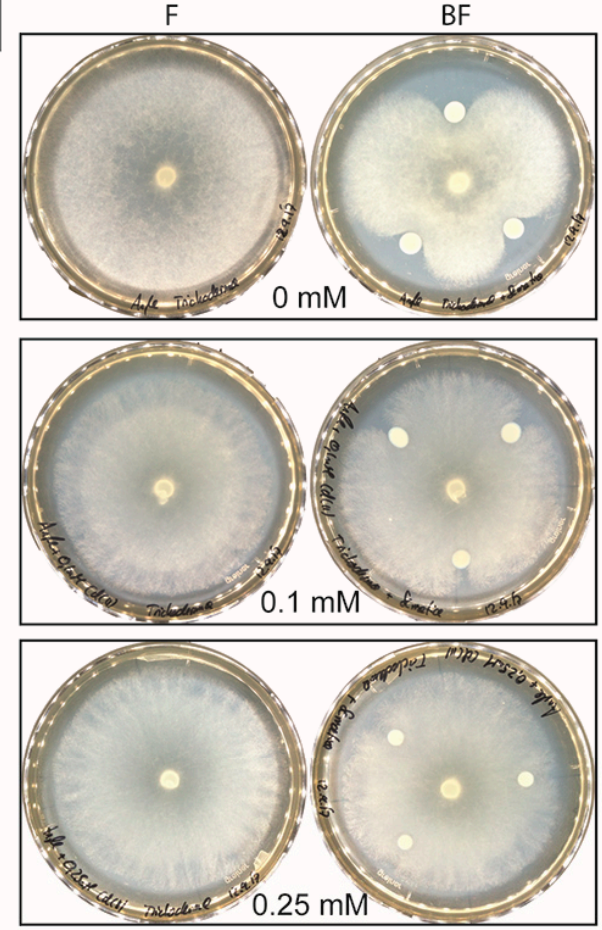

\section{B}

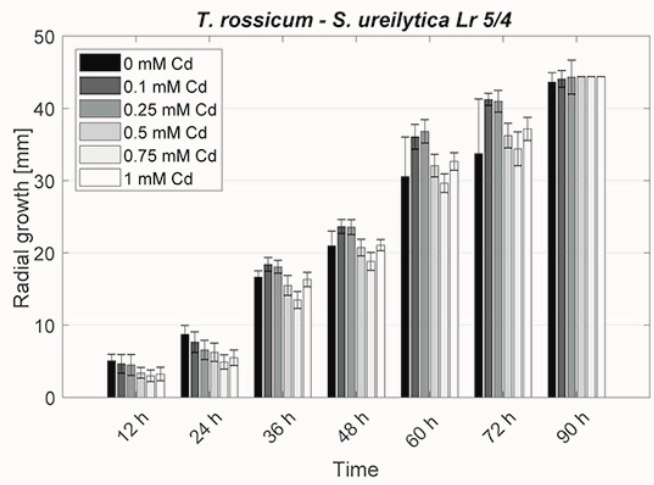

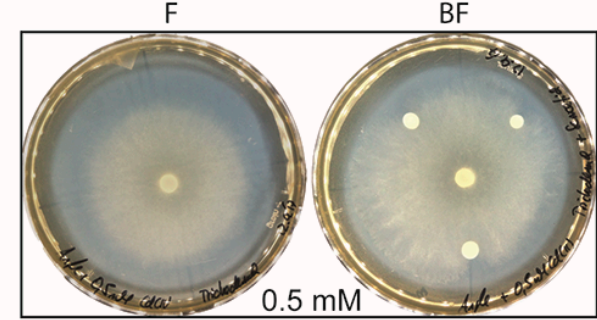
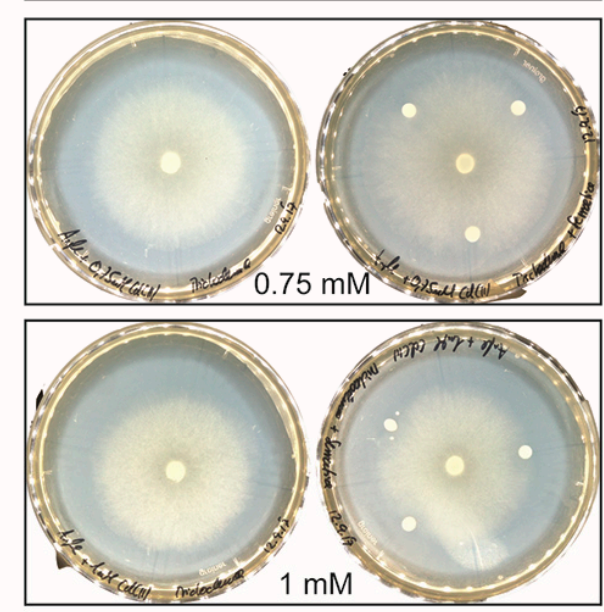

C

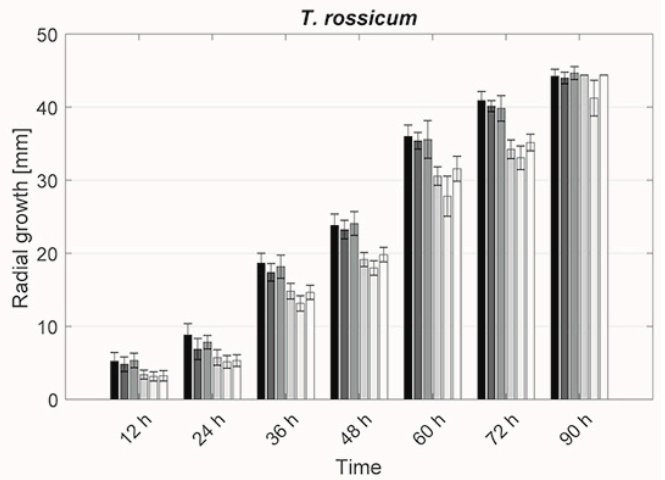

Figure A2. (A) Photographs of mono-cultures of Trichoderma rossicum (F panels) and co-cultures of $T$. rossicum + Serratia ureilytica Lr 5/4 (BF panels) in Angle medium (0 mM Cd) and Cd-containing Angle medium $(0.1,0.25,0.5,0.75$, and $1 \mathrm{mM} \mathrm{Cd})$; (B) Radial mycelial growth of T. rossicum in co-culture with S. ureilytica $\mathrm{Lr} 5 / 4$ in Angle medium (0 mM Cd) and Cd-containing Angle medium (0.5 and 1 $\mathrm{mM}$ Cd); (C) Radial mycelial growth of T. rossicum in mono-culture in Angle medium ( $0 \mathrm{mM} \mathrm{Cd}$ ) and Cd-containing Angle medium (0.1, 0.25, 0.5, 0.75, and $1 \mathrm{mM} \mathrm{Cd}$ ). 

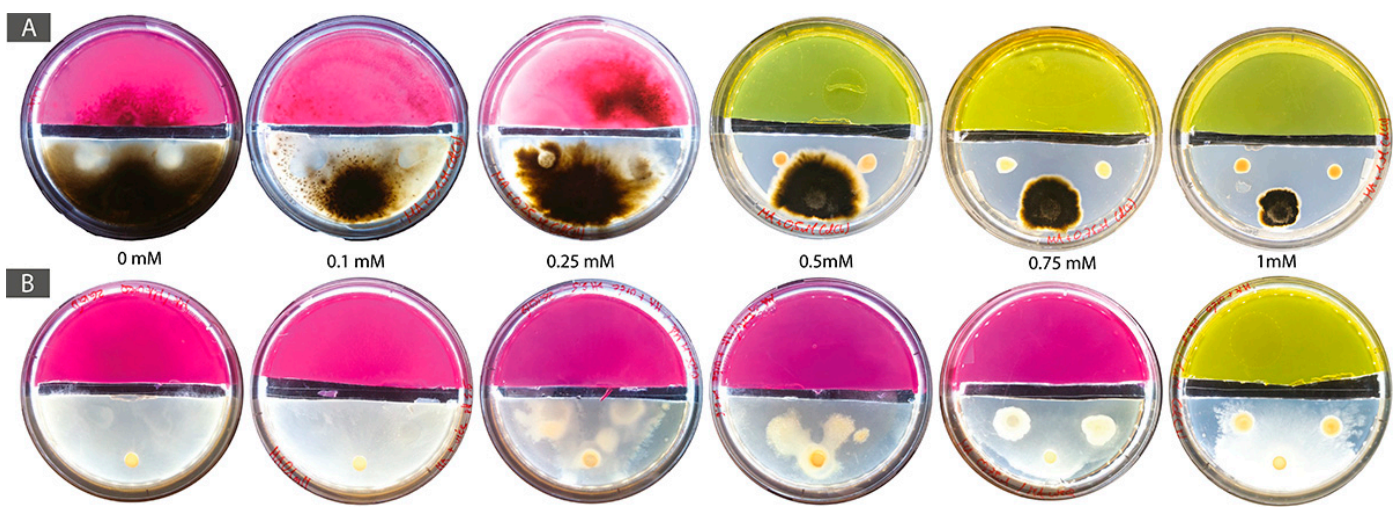

Figure A3. Experimental setting consisting of two-compartment systems in Petri dishes with a mobilization area (bottom part containing MA and Cd; $0 \mathrm{mM}$ control and 0.1, 0.25, 0.5, 0.75, and $1 \mathrm{mM} \mathrm{Cd}$ ) and an immobilization area (top colored part containing MA, $40 \mathrm{mM}$ urea, and phenol red as pH indicator). Co-cultures of (A) B. exigua and Pseudomonas sp. (B) T. rossicum and S. ureilytica Lr 5/4.

\section{References}

1. Robinson, B.H. E-waste: An assessment of global production and environmental impacts. Sci. Total Environ. 2009, 408, 183-191. [CrossRef] [PubMed]

2. Cui, J.; Zhang, L. Metallurgical recovery of metals from electronic waste: A review. J. Hazard. Mater. 2008, 158, 228-256. [CrossRef] [PubMed]

3. Widmer, R.; Oswald-Krapf, H.; Sinha-Khetriwal, D.; Schnellmann, M.; Böni, H. Global perspectives on e-waste. Environ. Impact Assess. Rev. 2005, 25, 436-458. [CrossRef]

4. Balde, C.P.; Wang, F.; Kuehr, R.; Huisman, J. The Global e-Waste Monitor 2014: Quantities, Flows and Resources; United Nations University: Tokyo, Japan, 2015; ISBN 978-92-808-4555-6.

5. Grant, K.; Goldizen, F.C.; Sly, P.D.; Brune, M.-N.; Neira, M.; van den Berg, M.; Norman, R.E. Health consequences of exposure to e-waste: A systematic review. Lancet Glob. Health 2013, 1, e350-e361. [CrossRef]

6. Lin, C.; Wen, L.; Tsai, Y. Applying decision-making tools to national e-waste recycling policy: An example of Analytic Hierarchy Process. Waste Manag. 2010, 30, 863-869. [CrossRef] [PubMed]

7. Cossu, R.; Williams, I.D. Urban mining: Concepts, terminology, challenges. Waste Manag. 2015, 45, 1-3. [CrossRef] [PubMed]

8. Zhuang, W.-Q.; Fitts, J.P.; Ajo-Franklin, C.M.; Maes, S.; Alvarez-Cohen, L.; Hennebel, T. Recovery of critical metals using biometallurgy. Curr. Opin. Biotechnol. 2015, 33, 327-335. [CrossRef] [PubMed]

9. Rawlings, D.E. Heavy Metal Mining Using Microbes. Annu. Rev. Microbiol. 2002, 56, 65-91. [CrossRef] [PubMed]

10. Harms, H.; Schlosser, D.; Wick, L.Y. Untapped potential: Exploiting fungi in bioremediation of hazardous chemicals. Nat. Rev. Microbiol. 2011, 9, 177-192. [CrossRef] [PubMed]

11. Gadd, G.M. Metals, minerals and microbes: Geomicrobiology and bioremediation. Microbiology 2010, 156, 609-643. [CrossRef] [PubMed]

12. Gadd, G.M. Geomycology: Biogeochemical transformations of rocks, minerals, metals and radionuclides by fungi, bioweathering and bioremediation. Mycol. Res. 2007, 111, 3-49. [CrossRef] [PubMed]

13. Nies, D.H. Efflux-mediated heavy metal resistance in prokaryotes. FEMS Microbiol. Rev. 2003, 27, 313-339. [CrossRef]

14. Gadd, G.M.; Griffiths, A.J. Microorganisms and heavy metal toxicity. Microb. Ecol. 1977, 4, $303-317$. [CrossRef] [PubMed]

15. Gadd, G. Metals and microorganisms: A problem of definition. FEMS Microbiol. Lett. 1992, 100, $197-203$. [CrossRef] [PubMed]

16. Fomina, M.; Hillier, S.; Charnock, J.M.; Melville, K.; Alexander, I.J.; Gadd, G.M. Role of Oxalic Acid Overexcretion in Transformations of Toxic Metal Minerals by Beauveria caledonica. Appl. Environ. Microbiol. 2005, 71, 371-381. [CrossRef] [PubMed]

17. Gadd, G.M. Interactions of fungip with toxic metals. New Phytol. 1993, 124, 25-60. [CrossRef] 
18. Brandl, H.; Faramarzi, M.A. Microbe-metal-interactions for the biotechnological treatment of metal-containing solid waste. China Particuol. 2006, 4, 93-97. [CrossRef]

19. Rawlings, D.E.; Johnson, D.B. The microbiology of biomining: Development and optimization of mineral-oxidizing microbial consortia. Microbiology 2007, 153, 315-324. [CrossRef] [PubMed]

20. Schippers, A.; Glombitza, F.; Sand, W. Geobiotechnology I. In Advances in Biochemical Engineering/Biotechnology; Springer: Berlin/Heidelberg, Germany, 2014; Volume 141, ISBN 978-3-642-54709-6.

21. Torsvik, V.; Øvreås, L. Microbial diversity and function in soil: From genes to ecosystems. Curr. Opin. Microbiol. 2002, 5, 240-245. [CrossRef]

22. Or, D.; Smets, B.F.; Wraith, J.M.; Dechesne, A.; Friedman, S.P. Physical constraints affecting bacterial habitats and activity in unsaturated porous media-A review. Adv. Water Resour. 2007, 30, 1505-1527. [CrossRef]

23. Boer, W.; de Folman, L.B.; Summerbell, R.C.; Boddy, L. Living in a fungal world: Impact of fungi on soil bacterial niche development. FEMS Microbiol. Rev. 2005, 29, 795-811. [CrossRef] [PubMed]

24. Dechesne, A.; Wang, G.; Gulez, G.; Or, D.; Smets, B.F. Hydration-controlled bacterial motility and dispersal on surfaces. Proc. Natl. Acad. Sci. USA 2010, 107, 14369-14372. [CrossRef] [PubMed]

25. Harshey, R.M. Bacterial Motility on a Surface: Many Ways to a Common Goal. Annu. Rev. Microbiol. 2003, 57, 249-273. [CrossRef] [PubMed]

26. Warmink, J.A.; Nazir, R.; Corten, B.; van Elsas, J.D. Hitchhikers on the fungal highway: The helper effect for bacterial migration via fungal hyphae. Soil Biol. Biochem. 2011, 43, 760-765. [CrossRef]

27. Kershaw, M.J.; Talbot, N.J. Hydrophobins and Repellents: Proteins with Fundamental Roles in Fungal Morphogenesis. Fungal Genet. Biol. 1998, 23, 18-33. [CrossRef] [PubMed]

28. Wösten, H.A.B. Hydrophobins: Multipurpose Proteins. Annu. Rev. Microbiol. 2001, 55, 625-646. [CrossRef] [PubMed]

29. Klein, D.A.; Paschke, M.W. Filamentous Fungi: The Indeterminate Lifestyle and Microbial Ecology. Microb. Ecol. 2004, 47. [CrossRef] [PubMed]

30. Boswell, G.P.; Jacobs, H.; Davidson, F.A.; Gadd, G.M.; Ritz, K. Functional Consequences of Nutrient Translocation in Mycelial Fungi. J. Theor. Biol. 2002, 217, 459-477. [CrossRef] [PubMed]

31. Kohlmeier, S.; Smits, T.H.M.; Ford, R.M.; Keel, C.; Harms, H.; Wick, L.Y. Taking the fungal highway: Mobilization of pollutant-degrading bacteria by fungi. Environ. Sci. Technol. 2005, 39, 4640-4646. [CrossRef] [PubMed]

32. Benedict, C.V.; Cameron, J.A.; Huang, S.J. Polycaprolactone degradation by mixed and pure cultures of bacteria and a yeast. J. Appl. Polym. Sci. 1983, 28, 335-342. [CrossRef]

33. Senevirate, G.; Tennakoon, N.S.; Weerasekara, M.; Nandasena, K.A. Polyethylene Biodegradation by a Developed Penicillium-Bacillus Biofilm. Curr. Sci. 2006, 90, 20-21.

34. Wick, L.Y.; Remer, R.; Würz, B.; Reichenbach, J.; Braun, S.; Schäfer, F.; Harms, H. Effect of Fungal Hyphae on the Access of Bacteria to Phenanthrene in Soil. Environ. Sci. Technol. 2007, 41, 500-505. [CrossRef] [PubMed]

35. Worrich, A.; Stryhanyuk, H.; Musat, N.; König, S.; Banitz, T.; Centler, F.; Frank, K.; Thullner, M.; Harms, H.; Richnow, H.-H.; et al. Mycelium-mediated transfer of water and nutrients stimulates bacterial activity in dry and oligotrophic environments. Nat. Commun. 2017, 8, 15472. [CrossRef] [PubMed]

36. Martin, G.; Guggiari, M.; Bravo, D.; Zopfi, J.; Cailleau, G.; Aragno, M.; Job, D.; Verrecchia, E.; Junier, P. Fungi, bacteria and soil $\mathrm{pH}$ : The oxalate-carbonate pathway as a model for metabolic interaction: Bacteria/fungi interactions and soil pH. Environ. Microbiol. 2012, 14, 2960-2970. [CrossRef] [PubMed]

37. Kaya, M. Recovery of metals and nonmetals from electronic waste by physical and chemical recycling processes. Waste Manag. 2016, 57, 64-90. [CrossRef] [PubMed]

38. Trevors, J.T.; Stratton, G.W.; Gadd, G.M. Cadmium transport, resistance, and toxicity in bacteria, algae, and fungi. Can. J. Microbiol. 1986, 32, 447-464. [CrossRef] [PubMed]

39. Puckett, J.; Byster, L.; Westervelt, S.; Gutierrez, R.; Davis, S.; Hussain, A.; Dutta, M. Exporting Harm: The High-Tech Trashing of Asia; Basel Action Network: Seattle, WA, USA, 2002; Volume 3.

40. Fernando, Q. Metal Speciation in Environmental and Biological Systems. Environ. Health Perspect. 1995, 103, 13. [CrossRef] [PubMed]

41. Vig, K. Bioavailability and toxicity of cadmium to microorganisms and their activities in soil: A review. Adv. Environ. Res. 2003, 8, 121-135. [CrossRef]

42. Ratte, H.T. Bioaccumulation and toxicity of silver compounds: A review. Environ. Toxicol. Chem. 1999, 18, 89-108. [CrossRef] 
43. Reith, F.; Lengke, M.F.; Falconer, D.; Craw, D.; Southam, G. The geomicrobiology of gold. ISME J. 2007, 1, 567-584. [CrossRef] [PubMed]

44. Wu, C.; Luo, Y.; Deng, S.; Teng, Y.; Song, J. Spatial characteristics of cadmium in topsoils in a typical e-waste recycling area in southeast China and its potential threat to shallow groundwater. Sci. Total Environ. 2014, 472, 556-561. [CrossRef] [PubMed]

45. Johnson, D.B. Biomining-Biotechnologies for extracting and recovering metals from ores and waste materials. Curr. Opin. Biotechnol. 2014, 30, 24-31. [CrossRef] [PubMed]

46. Quezada-Hinojosa, R.P.; Föllmi, K.B.; Verrecchia, E.; Adatte, T.; Matera, V. Speciation and multivariable analyses of geogenic cadmium in soils at Le Gurnigel, Swiss Jura Mountains. CATENA 2015, 125, 10-32. [CrossRef]

47. Federal Authorities of the Swiss Confederation RS 814.12 Ordonnance sur les Atteintes Portées aux Sols (OSol). Annexe 2, Valeurs Indicatives, Seuils d'Investigation et Valeurs d'Assainissement pour les Métaux Lourds et le Fluor Dans les Sols. Available online: https:/ / www.admin.ch/opc/fr/classified-compilation/ 19981783/index.html (accessed on 15 January 2018).

48. Simon, A.; Bindschedler, S.; Job, D.; Wick, L.Y.; Filippidou, S.; Kooli, W.M.; Verrecchia, E.P.; Junier, P. Exploiting the fungal highway: Development of a novel tool for the in situ isolation of bacteria migrating along fungal mycelium. FEMS Microbiol. Ecol. 2015, 91. [CrossRef] [PubMed]

49. Altschul, S.F.; Gish, W.; Miller, W.; Myers, E.W.; Lipman, D.J. Basic local alignment search tool. J. Mol. Biol. 1990, 215, 403-410. [CrossRef]

50. Gola, D.; Dey, P.; Bhattacharya, A.; Mishra, A.; Malik, A.; Namburath, M.; Ahammad, S.Z. Multiple heavy metal removal using an entomopathogenic fungi Beauveria bassiana. Bioresour. Technol. 2016, 218, 388-396. [CrossRef] [PubMed]

51. Mohammadian Fazli, M.; Soleimani, N.; Mehrasbi, M.; Darabian, S.; Mohammadi, J.; Ramazani, A. Highly cadmium tolerant fungi: Their tolerance and removal potential. J. Environ. Health Sci. Eng. 2015, 13. [CrossRef] [PubMed]

52. Bravo, D.; Cailleau, G.; Bindschedler, S.; Simon, A.; Job, D.; Verrecchia, E.; Junier, P. Isolation of oxalotrophic bacteria able to disperse on fungal mycelium. FEMS Microbiol. Lett. 2013, 348, 157-166. [CrossRef] [PubMed]

53. Finlay, R.D. Ecological aspects of mycorrhizal symbiosis: With special emphasis on the functional diversity of interactions involving the extraradical mycelium. J. Exp. Bot. 2008, 59, 1115-1126. [CrossRef] [PubMed]

54. Filippidou, S. Sporulation and Metabolism of Endospore-Forming Firmicutes under Conditions Limiting for Growth and Survival. Available online: https://explore.rero.ch/fr_CH/nj/result/L/ VIRMU19SRVJPUjAwODQzMDM5MQ== (accessed on 17 January 2018).

55. Angle, J.S.; McGrath, S.P.; Chaney, R.L. New Culture Medium Containing Ionic Concentrations of Nutrients Similar to Concentrations Found in the Soil Solution. Appl. Environ. Microbiol. 1991, 57, 3674-3676. [PubMed]

56. Miquel Guennoc, C.; Rose, C.; Guinnet, F.; Miquel, I.; Labbé, J.; Deveau, A. A New Method for Qualitative Multi-scale Analysis of Bacterial Biofilms on Filamentous Fungal Colonies Using Confocal and Electron Microscopy. J. Vis. Exp. 2017, 119. [CrossRef] [PubMed]

57. Dykstra, M.J.; Reuss, L.E. Biological Electron Microscopy: Theory, Techniques, and Troubleshooting, 2nd ed.; Kluwer Academic/Plenum Publishers: New York, NY, USA, 2003; ISBN 978-0-306-47749-2.

58. Congeevaram, S.; Dhanarani, S.; Park, J.; Dexilin, M.; Thamaraiselvi, K. Biosorption of chromium and nickel by heavy metal resistant fungal and bacterial isolates. J. Hazard. Mater. 2007, 146, 270-277. [CrossRef] [PubMed]

59. Egerton-Warburton, L.M.; Griffin, B.J. Differential responses of Pisolithus tinctorius isolates to aluminum in vitro. Can. J. Bot. 1995, 73, 1229-1233. [CrossRef]

60. Long, J.; Li, H.; Jiang, D.; Luo, D.; Chen, Y.; Xia, J.; Chen, D. Biosorption of strontium(II) from aqueous solutions by Bacillus cereus isolated from strontium hyperaccumulator Andropogon gayanus. Process Saf. Environ. Prot. 2017, 111, 23-30. [CrossRef]

61. Nongmaithem, N.; Roy, A.; Bhattacharya, P.M. Screening of Trichoderma isolates for their potential of biosorption of nickel and cadmium. Braz. J. Microbiol. 2016, 47, 305-313. [CrossRef] [PubMed]

62. Zouboulis, A.; Loukidou, M.; Matis, K. Biosorption of toxic metals from aqueous solutions by bacteria strains isolated from metal-polluted soils. Process Biochem. 2004, 39, 909-916. [CrossRef]

63. Horiike, T.; Yamashita, M. A New Fungal Isolate, Penidiella sp. Strain T9, Accumulates the Rare Earth Element Dysprosium. Appl. Environ. Microbiol. 2015, 81, 3062-3068. [CrossRef] [PubMed] 
64. Blaudez, D.; Jacob, C.; Turnau, K.; Colpaert, J.V.; Ahonen-Jonnarth, U.; Finlay, R.; Botton, B.; Chalot, M. Differential responses of ectomycorrhizal fungi to heavy metals in vitro. Mycol. Res. 2000, 104, 1366-1371. [CrossRef]

65. Jones, M.D.; Hutchinson, T.C. The effects of nickel and copper on the axenic growth of ectomycorrhizal fungi. Can. J. Bot. 1988, 66, 119-124. [CrossRef]

66. Ledin, M. Accumulation of metals by microorganisms-Processes and importance for soil systems. Earth-Sci. Rev. 2000, 51, 1-31. [CrossRef]

67. Ellis, R.J.; Morgan, P.; Weightman, A.J.; Fry, J.C. Cultivation-dependent and -independent approaches for determining bacterial diversity in heavy-metal-contaminated soil. Appl. Environ. Microbiol. 2003, 69, 3223-3230. [CrossRef] [PubMed]

68. Ramsay, L.; Sayer, J.; Gadd, G.; Gow, N.; Robson, G. Stress responses of fungal colonies towards toxic metals. In The Fungal Colony; Cambridge University Press: Cambridge, UK, 1999; pp. 178-200.

69. Pradhan, S.; Singh, S.; Rai, L.C. Characterization of various functional groups present in the capsule of Microcystis and study of their role in biosorption of Fe, Ni and Cr. Bioresour. Technol. 2007, 98, 595-601. [CrossRef] [PubMed]

70. Volesky, B. Biosorption and me. Water Res. 2007, 41, 4017-4029. [CrossRef] [PubMed]

71. Shuttleworth, K.L.; Unz, R.F. Sorption of heavy metals to the filamentous bacterium Thiothrix strain A1. Appl. Environ. Microbiol. 1993, 59, 1274-1282. [PubMed]

72. Hughes, M.N.; Poole, R.K. Metal speciation and microbial growth-The hard (and soft) facts. J. Gen. Microbiol. 1991, 137, 725-734. [CrossRef]

73. Kumari, D.; Qian, X.-Y.; Pan, X.; Achal, V.; Li, Q.; Gadd, G.M. Microbially-Induced Carbonate Precipitation for Immobilization of Toxic Metals. In Advances in Applied Microbiology; Elsevier: Amsterdam, The Netherlands, 2016; Volume 94, pp. 79-108. ISBN 978-0-12-804803-0.

74. Li, Q.; Csetenyi, L.; Paton, G.I.; Gadd, G.M. $\mathrm{CaCO}_{3}$ and $\mathrm{SrCO}_{3}$ bioprecipitation by fungi isolated from calcareous soil: Metal carbonate biomineralization by fungi. Environ. Microbiol. 2015, 17, 3082-3097. [CrossRef] [PubMed]

75. Li, Q.; Csetenyi, L.; Gadd, G.M. Biomineralization of Metal Carbonates by Neurospora crassa. Environ. Sci. Technol. 2014, 48, 14409-14416. [CrossRef] [PubMed]

76. Fogarty, R.V.; Tobin, J.M. Fungal melanins and their interactions with metals. Enzyme Microb. Technol. 1996, 19, 311-317. [CrossRef]

77. Purvis, O.W.; Bailey, E.H.; McLean, J.; Kasama, T.; Williamson, B.J. Uranium Biosorption by the Lichen Trapelia involuta at a Uranium Mine. Geomicrobiol. J. 2004, 21, 159-167. [CrossRef]

78. Fomina, M.; Gadd, G.M. Metal sorption by biomass of melanin-producing fungi grown in clay-containing medium. J. Chem. Technol. Biotechnol. 2003, 78, 23-34. [CrossRef]

79. Pons, M.P.; Fusté, M.C. Uranium uptake by immobilized cells of Pseudomonas strain EPS 5028. Appl. Microbiol. Biotechnol. 1993, 39, 661-665. [CrossRef]

80. De Rome, L.; Gadd, G.M. Use of pelleted and immobilized yeast and fungal biomass for heavy metal and radionuclide recovery. J. Ind. Microbiol. 1991, 7, 97-104. [CrossRef]

(C) 2018 by the authors. Licensee MDPI, Basel, Switzerland. This article is an open access article distributed under the terms and conditions of the Creative Commons Attribution (CC BY) license (http://creativecommons.org/licenses/by/4.0/). 